\title{
Anti-Hypertensive Herbs and Their Mechanisms of Action: Part II
}

\author{
M. Akhtar Anwar ${ }^{1+}$, Sara S. Al Disi ${ }^{1+}$ and Ali H. Eid ${ }^{1,2 *}$ \\ ${ }^{1}$ Department of Biological and Environmental Sciences, Qatar University, Doha, Qatar, ${ }^{2}$ Department of Pharmacology and \\ Toxicology, Faculty of Medicine, American University of Beirut, Beirut, Lebanon
}

OPEN ACCESS

Edited by:

Hibah Omar Awwad,

University of Oklahoma Health

Sciences Center, USA

Reviewed by:

Javier Angulo,

Hospital Ramón y Cajal, Spain

Brett M. Mitchell,

Texas A\&M Health Science Center,

USA

${ }^{*}$ Correspondence:

Ali H. Eid

ali.eid@qu.edu.qa

${ }^{\dagger}$ These authors have contributed equally to this work.

Specialty section:

This article was submitted to Cardiovascular and Smooth Muscle

Pharmacology,

a section of the journal

Frontiers in Pharmacology

Received: 13 October 2015

Accepted: 22 February 2016

Published: 08 March 2016

Citation:

Anwar MA, Al Disi SS and Eid AH (2016) Anti-Hypertensive Herbs and Their Mechanisms of Action: Part II.

Front. Pharmacol. 7:50.

doi: 10.3389/fphar.2016.00050
Traditional medicine has a history extending back to thousands of years, and during the intervening time, man has identified the healing properties of a very broad range of plants. Globally, the use of herbal therapies to treat and manage cardiovascular disease (CVD) is on the rise. This is the second part of our comprehensive review where we discuss the mechanisms of plants and herbs used for the treatment and management of high blood pressure. Similar to the first part, PubMed and ScienceDirect databases were utilized, and the following keywords and phrases were used as inclusion criteria: hypertension, high blood pressure, herbal medicine, complementary and alternative medicine, endothelial cells, nitric oxide (NO), vascular smooth muscle cell (VSMC) proliferation, hydrogen sulfide, nuclear factor kappa-B (NF-kB), oxidative stress, and epigenetics/epigenomics. Each of the aforementioned keywords was co-joined with plant or herb in question, and where possible with its constituent molecule(s). This part deals in particular with plants that are used, albeit less frequently, for the treatment and management of hypertension. We then discuss the interplay between herbs/prescription drugs and herbs/epigenetics in the context of this disease. The review then concludes with a recommendation for more rigorous, well-developed clinical trials to concretely determine the beneficial impact of herbs and plants on hypertension and a disease-free living.

Keywords: herbal medicine, hypertension, endothelial/vascular smooth muscle cells, oxidative stress, inflammation, nitric oxide, epigenetics

\section{HERBS AND SPICES LESS COMMONLY USED FOR TREATMENT OF HYPERTENSION}

In the first part of this review (Al Disi et al., 2015), we discussed the molecular and cellular mechanisms involved in the pathogenesis of hypertension. We followed that by an in-depth discussion of the different herbs/spices that are most commonly used for the management and treatment of hypertension (Al Disi et al., 2015). However, there are many other herbs/spices that appear to have significant effects in favorably modulating high blood pressure. Yet, these herbs are not very commonly used, due to several reasons, such as restriction of their growth habitat or use by few or disparate nations and tribal groups. Moreover, limited knowledge in terms of research evidence and wisdom restricted to certain cultures, tribal groups, or nations of small effective population size are potential contributors to this infrequent use and scarcity of research-based evidence.

Here, in this second part of our review, we discuss the effects and mechanisms of action for herbs/spices that are less commonly consumed. We present these plants in an alphabetical order 
and then summarize their effects and mechanisms of action. Attention in the tables is given to plants that have antioxidant (Table 1), vasorelaxant (Table 2), anti-inflammatory (Table 3), anti-proliferative (Table 4), or diuretic effects (Table 5). Table 6 then summarizes the findings for the plants/herbs which have been studied in clinical trials.

\section{Acorus calamus (Sweet Flag or Calamus)}

Different solvent extracts of Acorus calamus have been reported to decrease mean arterial pressure (MAP) in normotensive rats (Shah and Gilani, 2009; Table 2). This plant can cause vasoconstrictive or vasodilatory activities on baseline and high $\mathrm{K}^{+}$-induced contractions in rabbit aorta, suggesting that it may regulate vascular tone (Shah and Gilani, 2009). Its effects seem to be mediated through a $\mathrm{Ca}^{2+}$-dependent mechanism (Shah and Gilani, 2009).

\section{Agelanthus dodoneifolius (Mistletoe)}

Ethanolic extracts of Agelanthus dodoneifolius (mistletoe) (0.001$3 \mathrm{mg} / \mathrm{ml}$ ) showed dose-dependent relaxing effects on rat isolated aortic rings (Ouedraogo et al., 2011). In addition, $0.01-10 \mathrm{mg} / \mathrm{ml}$ of the same extract decreased systolic blood pressure (SBP) and diastolic blood pressure (DBP) in normotensive rats (Ouedraogo et al., 2011; Table 2). The active component with the most potent activity was identified as dihydropyranone dodoneine (Ouedraogo et al., 2011). While this plant appears to exhibit antioxidant activity (Builders et al., 2012; Table 1), further investigations are warranted to decipher the mechanism relevant to hypotensive effect. A potential mechanism was recently proposed, wherein dodoneine was shown to induce vasorelaxation by inhibiting carbonic anhydrase and activating calcium-gated potassium $\left(\mathrm{K}_{\mathrm{Ca}}\right)$ channels (Carre et al., 2015) as well as precipitating a negative inotropic effect on the rat heart (Carré et al., 2014).

\section{Allium cepa (Onion)}

Allium cepa, or onion, has been reported to reduce BP in fructose-fed (Naseri et al., 2008; Table 2) and anesthetized normotensive rats (Brankovic et al., 2011). Aqueous extracts of onion $(400 \mathrm{mg} / \mathrm{kg} /$ day) increase expression of endothelial nitric oxide synthase (eNOS) but decrease that of vascular cell adhesion molecule 1 (VCAM-1; Vazquez-Prieto et al., 2011). In rat isolated thoracic aorta, $A$. cepa $(0.06-2.00 \mathrm{mg} / \mathrm{ml})$ attenuated both phenylephrine- and $\mathrm{KCl}$-induced contractions (Naseri et al., 2008). Removal of endothelium or inhibition of NO, cyclic guanosine monophosphate (cGMP), or prostaglandins did not affect the vasorelaxant action of onion (Naseri et al., 2008). These data suggest an endothelium-independent mechanism, possibly through the regulation of extracellular $\mathrm{Ca}^{2+}$ levels (Naseri et al., 2008). Indeed, the investigators implied that antioxidants and the polyphenol quercetin may play a role in relaxing the rat aorta (Naseri et al., 2008; Table 2). In contrast to the main conduit vessel, small resistance-size arteries of the rat mesentery, when exposed to a high cholesterol diet enriched with $10 \%$ onion powder, demonstrated an improved endothelium-dependent relaxation (comparable to the control group) than the impaired arterial relaxation observed with the group on high cholesterol diet alone (GonzálezPeña et al., 2014). This improvement appears to be due to suppression of nicotinamide adenine dinucleotide phosphate (NADPH)-oxidase activity along with a concomitant increase in antioxidant kinetics of superoxide dismutase (SOD) and glutathione peroxidase (GPX) enzymes (González-Peña et al., 2014).

\section{Alpinia zerumbet (Shel Ginger)}

Alpinia zerumbet, a west Asian plant, has been reported for its modest hypotensive effects (Lahlou et al., 2003; de Moura et al., 2005; Shen et al., 2012; da Cunha et al., 2013; Table 2). There is a growing consensus on its vasorelaxant responses, either through effects on endothelial cells (de Moura et al., 2005; Shen et al., 2012; da Cunha et al., 2013) or VSMCs (Lahlou et al., 2003). Specifically, the methanolic extract of its leaves (100 and $300 \mu \mathrm{g} / \mathrm{ml}$ ) induced vasodilation by increasing NO or cGMP production in deoxycorticosterone acetate (DOCA)-salt-treated rats (de Moura et al., 2005). Interestingly, components of its essential oils $(1-20 \mathrm{mg} / \mathrm{kg})$ inhibit $\mathrm{Ca}^{2+}$ channels of rat thoracic aortic rings (da Cunha et al., 2013). In another study, $0.1 \mathrm{mg} / \mathrm{L}$ of $A$. zerumbet's essential oils were reported to reduce levels of oxidized lowdensity lipoprotein (LDL) in plasma, thereby highlighting their potential in preventing endothelial damage (Shen et al., 2012; Table 1).

\section{Apocynum venetum (Dogbane or Indian Hemp)}

Extracts of dogbane or Indian hemp's (common names) leaves have been reported to lower BP in different animal models (Ma and Chen, 1989; Kim et al., 2000; Lau et al., 2012; Xie et al., 2012; Table 2). Moreover, these extracts $(10 \mu \mathrm{g} / \mathrm{ml})$ induce vasorelaxation in rat aortic rings by increasing NO production and scavenging reactive oxygen species (ROS) (Lau et al., 2012; Table 1). Apparently, improvements in renal function are integral to the antihypertensive effect of this plant's extracts (Kim et al., 2000).

\section{Arctium Lappa (Burdock)}

Arctium lappa, commonly known as burdock, is used for treatment of many ailments including hypertension (Lee Y. J. et al., 2012; Table 2). Evidence shows that this plant possesses ROS scavenging activity (Predes et al., 2011; Table 1), prevents vascular inflammation (Lee Y. J. et al., 2012; Wang et al., 2016; Table 3), and promotes vasorelaxation (Lee Y. J. et al., 2012; Table 2). Very recently, root extracts of this plant were shown to alleviate high fat diet-induced atherosclerotic lesions in quail (Wang et al., 2016). The underlying mechanisms for this protective effect appear to be due to the extracts' hypolipidemic and antioxidant capacities (Wang et al., 2016). Taken together, these activities could offer an explanation for the use of $A$. lappa as an antihypertensive agent.

One of the bioactive constituents found in dry seeds of burdock is arctigenin. It was recently found that arctigenin ameliorates endothelial dysfunction and reduces SBP in 
TABLE 1 | Less commonly used antihypertensive plants with antioxidant activity.

\begin{tabular}{|c|c|c|c|c|}
\hline Herb & Effect/Mechanism & Concentration/Dose & Experimental setting/Model & References \\
\hline Apocynum venetum & Scavenges ROS & $10 \mu \mathrm{g} / \mathrm{ml}$ & Rat isolated aortic rings & Lau et al., 2012 \\
\hline Cnidium monnieri & Increases antioxidants & $20 \mathrm{mg} / \mathrm{kg}$ & Renovascular hypertensive rats & Zhou et al., 2012 \\
\hline Cnidium officinale & Scavenges ROS & $0.32-200 \mu \mathrm{g} / \mathrm{ml}$ & DPPH enzymatic assay & Jeong et al., 2009 \\
\hline Desmodium gangeticum & Reduces ROS & $50-200 \mu \mathrm{g} / \mathrm{ml}$ & Isoproterenol-treated cardiomyocytes & Sankar et al., 2013 \\
\hline Ferula gummosa & Increases antioxidants & $90 \mathrm{mg} / \mathrm{kg}$ & SHR & Gholitabar and Roshan, 2013 \\
\hline Gastrodia elata Blume & Decreases LDL cholesterol & $6 \mathrm{mg} / \mathrm{kg} / \mathrm{day}$ & High fat-fed SHR & Lee O. H. et al., 2012 \\
\hline Kalanchoe pinnata & Increases antioxidants & $25-100 \mathrm{mg} / \mathrm{kg} /$ day & High salt-loaded rats & Bopda et al., 2014 \\
\hline Lepidium sativum & Scavenges ROS & $\begin{array}{l}500 \mu \mathrm{g} \text { (of the lyophilized extract } \\
\text { in a tube) }\end{array}$ & DPPH enzymatic assay & Kaur et al., 2013 \\
\hline Melothria maderaspatana & Increases antioxidants & 50,100, and $200 \mathrm{mg} / \mathrm{kg}$ & DOCA-salt hypertensive rats & Veeramani et al., 2011 \\
\hline Pueraria lobata & Scavenges oxidants & $\begin{array}{l}\mathrm{IC}_{50} \text { range: } 7.90 \text { to }>200 \mu \mathrm{g} / \mathrm{ml} \\
\text { (for different solvent-extractions) }\end{array}$ & $\begin{array}{l}\text { DPPH enzymatic assay (and other } \\
\text { in vitro assays) }\end{array}$ & Jin et al., 2012 \\
\hline \multirow[t]{2}{*}{ Radix Angelicae } & Increases antioxidants & $6.25-25 \mathrm{mg} / \mathrm{kg} / \mathrm{day}$ & $2 \mathrm{~K}-1 \mathrm{C}$ rats & Cao et al., 2013 \\
\hline & Decreases peroxidants & & & \\
\hline \multirow[t]{2}{*}{ Raphanus sativus } & Increases antioxidants & 30 and $90 \mathrm{mg} / \mathrm{kg}$ & SHR & Chung et al., 2012 \\
\hline & Scavenges oxidants & $\begin{array}{l}\mathrm{IC}_{50} \text { range: } 23-200 \mu \mathrm{g} / \mathrm{ml} \text { (for } \\
\text { different parameters using } \\
\text { different solvent-extractions) }\end{array}$ & DPPH enzymatic assay & Beevi et al., 2010 \\
\hline Rhus coriaria & Scavenges oxidants & $\begin{array}{l}\mathrm{IC}_{50} \text { range: } 0.71 \text { to }>12 \mu \mathrm{g} / \mathrm{ml} \\
\text { (for different fractions) }\end{array}$ & DPPH enzymatic assay & Kosar et al., 2007 \\
\hline Sambucus ebulus $L$. & Increases antioxidants & $200 \mathrm{ml} /$ day & Healthy humans & Ivanova et al., 2014 \\
\hline \multirow[t]{2}{*}{ Sesamum indicum } & Scavenges ROS & $25-1000 \mathrm{mg} / \mathrm{ml}$ & DPPH enzymatic assay & Visavadiya et al., 2009 \\
\hline & Inhibits LDL peroxidation & & $\begin{array}{l}\text { Mitochondrial fraction and human } \\
\text { serum }\end{array}$ & \\
\hline
\end{tabular}




\section{TABLE 1 | Continued}

\begin{tabular}{|c|c|c|c|c|}
\hline Herb & Effect/Mechanism & Concentration/Dose & Experimental setting/Model & References \\
\hline \multirow[t]{2}{*}{ Stephania tetrandra } & $\begin{array}{l}\text { Reduces iNOS and COX-2 } \\
\text { expression }\end{array}$ & $\begin{array}{l}100 \mu \mathrm{M} \text { of its active compound, } \\
\text { tetrandrine }\end{array}$ & Human monocytic cells & Wu and Ng, 2007 \\
\hline & $\begin{array}{l}\text { Reduces production of } \\
\text { oxidants }\end{array}$ & $\begin{array}{l}25-50 \mu \mathrm{M} \text { of its active } \\
\text { compound, tetrandrine }\end{array}$ & LPS-stimulated microglia & Xue et al., 2008 \\
\hline Suaeda asparagoides & Scavenges ROS & $\begin{array}{l}\mathrm{IC}_{50} \text { range: } 9-42 \mu \mathrm{g} / \mathrm{ml} \text { (for } \\
\text { different solvent-extractions) }\end{array}$ & DPPH enzymatic assay & Park et al., 2007 \\
\hline Tribulus terrestris & Reduces $\mathrm{H}_{2} \mathrm{O}_{2}$ & $\begin{array}{l}0.240 \mathrm{mg} / \mathrm{ml} \text { of the plant's total } \\
\text { saponins }\end{array}$ & $\begin{array}{l}\text { Primary VSMCs from aorta of newborn } \\
\text { calves }\end{array}$ & Li et al., 2013 \\
\hline \multirow[t]{2}{*}{ Tropaeolum majus $L$} & Reduces ACE & $\begin{array}{l}300 \mathrm{mg} / \mathrm{kg} \text { ethanolic extract, } \\
200 \mathrm{mg} / \mathrm{kg} \text { purified fraction, } \\
10 \mathrm{mg} / \mathrm{kg} \text { isoquercitrin }\end{array}$ & SHRs & $\begin{array}{l}\text { Gasparotto Junior et al., } \\
2012\end{array}$ \\
\hline & Reduces ROS & $10 \mathrm{mg} / \mathrm{kg}$ & & \\
\hline \multirow[t]{3}{*}{ Viscum articulatum Burm } & $\begin{array}{l}\text { Inhibits cardiac lipid } \\
\text { peroxidation }\end{array}$ & $60 \mathrm{mg} / \mathrm{kg} /$ day & Glucocorticoid-treated rats & Bachhav et al., 2011 \\
\hline & Increases NO & & & \\
\hline & Scavenges oxidants & $\begin{array}{l}\mathrm{ED}_{50} \text { range: } 34.1-63.3 \mu \mathrm{g} / \mathrm{ml} \text { (for } \\
\text { different compounds) }\end{array}$ & DPPH enzymatic assay & Kuo et al., 2010 \\
\hline
\end{tabular}

spontaneously hypertensive rats (SHRs; Liu Y. et al., 2015). The mechanism by which arctigenin seems to elicit its effects involves increased NO production as well as reduced levels of superoxide anion in thoracic aorta (Liu Y. et al., 2015). Interestingly, this bioactive ingredient was recently suggested to be a potential antihypertensive drug lead compound, owing to its newly discovered capacity as an antagonist of Mineralocorticoid receptor (Cheng et al., 2016). It is important to note here that although some report that this plant is popularly used for treatment of hypertension (Lee Y. J. et al., 2012), little evidence supports this notion; hence, we opted for including this plant among the herbs/plants that are less commonly used.

\section{Avena sativa (Common Oat)}

The lowering of blood pressure (BP) by the common oat is still debatable (Houston, 2005; Kochar et al., 2012). While some studies report significant falls in BP (Houston, 2005; Flint et al., 2009; Kochar et al., 2012), others have failed to detect any change (Davy et al., 2002; Houston, 2005; Kochar et al., 2012). In a clinical study, an intake of low-calorie diet with oats [45 g dry weight/(4.2 MJ dietary energy. d)] for a 6-week period had a greater effect on reducing BP than one without oats in healthy men and women (Saltzman et al., 2001). Indeed, another clinical study reported that oat-containing diets decrease the necessity for hypotensive therapy (Houston, 2005).

The hypotensive effect of oats is attributable to the presence of its soluble fibers (Flint et al., 2009) and avenanthramides (biphenolic molecules; Andersson and Hellstrand, 2012). Mechanisms by which this effect is enacted suggests that it due to several parameters, namely prevention of endothelial dysfunction (Guo et al., 2008; Flint et al., 2009; Kochar et al., 2012), decrease in TNF- $\alpha$ levels (Kochar et al., 2012), improved insulin sensitivity (Houston, 2005; Kochar et al., 2012), increased weight loss (Flint et al., 2009), inhibition of VSMC proliferation (Nie et al., 2006a,b), and increased NO production (Nie et al., 2006b). Following ingestion of oats, the soluble fiber $\beta$-glucan (linear, unbranched polysaccharide), is anaerobically broken-down by commensal microbiota into short-chain fatty acids such as butyrate, propionate and acetate (Andersson and Hellstrand, 2012). All of these compounds elicit arterial relaxation (Aaronson et al., 1996), which would cause a fall in $\mathrm{BP}$, and their synergistic effects may prove to be even more significant.

\section{Carthamus tinctorius L. (Safflower)}

Carthamus tinctorius L. is used in traditional Chinese medicine for the treatment of cerebrovascular and cardiovascular diseases (Wang et al., 2014). The safflower extract is commonly referred to as safflower yellow (SY). SY is a mixture of water-soluble chalcone compounds extracted from the plant flowers (Zhou et al., 2013). It has been shown that SY lowers BP as well as reduces renin activity and angiotensin II levels in SHRs (Zhou et al., 2013). Hydroxysafflor yellow A (HSYA; 0.1-3 mg/kg), the main bioactive component of SY, has been shown to reduce BP and heart rate of both normotensive rats and SHRs (Nie et al., 2012; Table 2). Its mode of action appears to be elicited by opening $\mathrm{K}_{\mathrm{ATP}}$ channels (Nie et al., 2012). Another report indicates that HSYA relaxes rat pulmonary artery by activating $\mathrm{K}_{\mathrm{v}}$ channels (Bai et al., 2012). In addition to lowering BP in healthy humans, safflower seed extract (2.1 g daily) also decreased both VCAM1 and LDL levels as well as reduced arterial stiffness (Koyama 
TABLE 2 | Less commonly used antihypertensive plants with vasorelaxant activity.

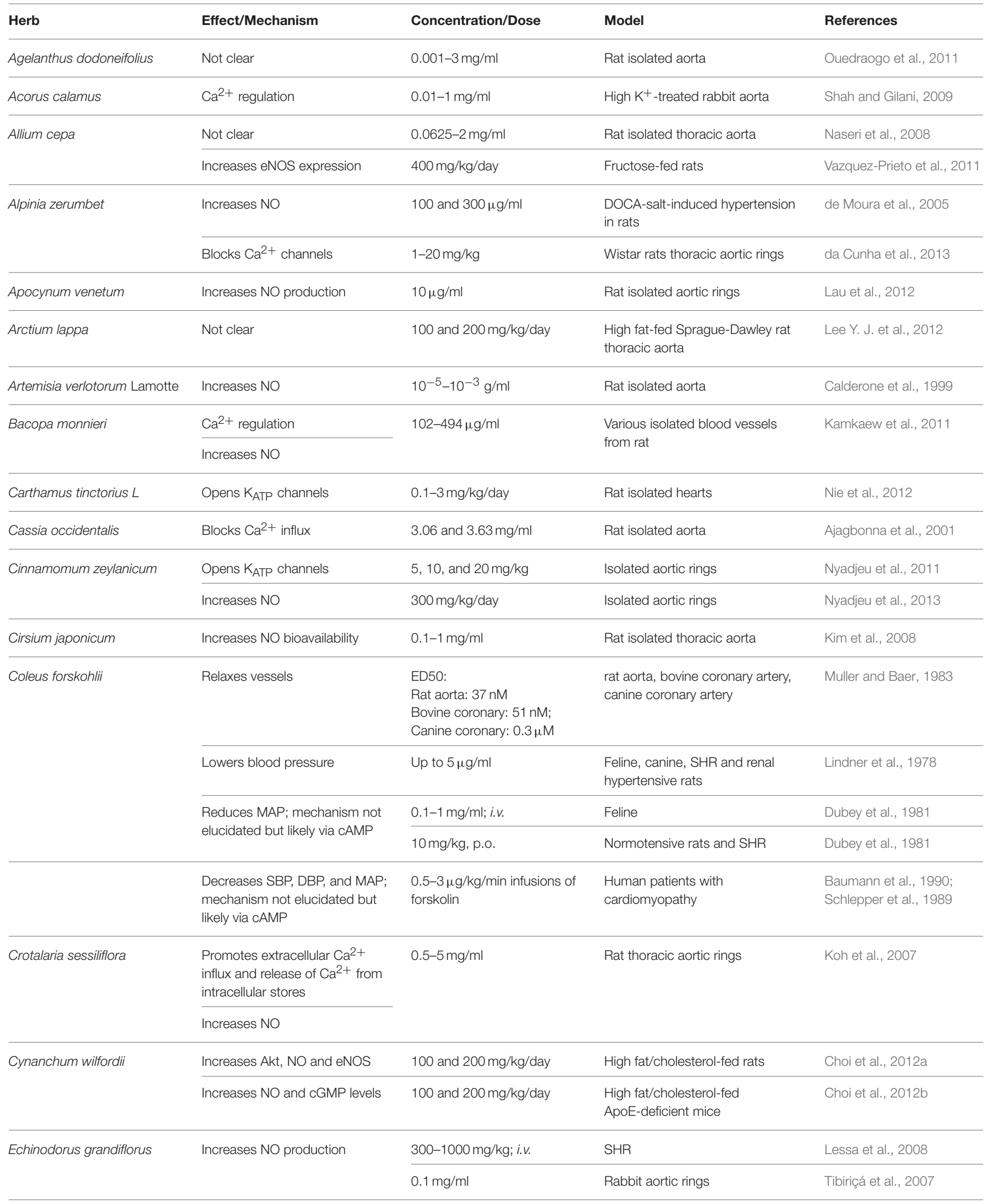




\section{TABLE 2 | Continued}

\begin{tabular}{|c|c|c|c|c|}
\hline Herb & Effect/Mechanism & Concentration/Dose & Model & References \\
\hline Elettaria cardamomum & Blocks $\mathrm{Ca}^{2+}$ channels & $2.94 \mathrm{mg} / \mathrm{ml}$ & Rat isolated aorta & Gilani et al., 2008 \\
\hline \multirow[t]{2}{*}{ Euphorbia humifusa } & $\mathrm{Ca}^{2+}$ regulation & $10^{-4}-10^{-7} \mathrm{~g} / \mathrm{ml}$ & Rat aortic rings & Wang et al., 2013 \\
\hline & Increases NO & & & \\
\hline Gentiana floribunda & Blocks $\mathrm{Ca}^{2+}$ channels & $0.3-1 \mathrm{mg} / \mathrm{ml}$ & Rat aorta & Khan et al., 2012 \\
\hline Geum japonicum & Increases NO & $30 \mu \mathrm{g} / \mathrm{ml}$ & Rat aortic rings & Xie et al., 2007 \\
\hline \multirow[t]{3}{*}{ Gynura procumbens } & Inhibits $\mathrm{Ca}^{2+}$ channels & $10^{-5}-10^{-3} \mathrm{~g} / \mathrm{ml}$ & Rat aortic rings & Hoe et al., 2011 \\
\hline & Increases NO & $500 \mathrm{mg} / \mathrm{kg}$ & SHR & Kim et al., 2006 \\
\hline & Opens $\mathrm{K}_{\text {ATP }}$ channels & 0.003 and $0.009 \mathrm{~g} / \mathrm{ml}$ & Rat isolated thoracic aortic rings & Ng et al., 2013 \\
\hline \multirow[t]{5}{*}{ Kaempferia parviflora } & Reduces $\mathrm{Ca}^{2+}$ influx & 10 and $100 \mu \mathrm{M}$ & Rat isolated aortic rings & Tep-Areenan et al., 2010 \\
\hline & Decreases defibrillation efficacy & $12.5-100 \mathrm{mg} / \mathrm{kg}$ & Porcine & $\begin{array}{l}\text { Weerateerangkul et al., } \\
2013\end{array}$ \\
\hline & Decreases $\mathrm{Ca}^{2+}$ & $75-300 \mu \mathrm{g} / \mathrm{mL}$ & Ventricular myocytes & $\begin{array}{l}\text { Weerateerangkul et al., } \\
2012\end{array}$ \\
\hline & Increases NO signaling & $1-100 \mu \mathrm{M}$ & Rat isolated aortic rings & Tep-Areenan et al., 2010 \\
\hline & & $100 \mathrm{mg} / \mathrm{kg}$ & Rat heart & $\begin{array}{l}\text { Weerateerangkul et al., } \\
2012\end{array}$ \\
\hline Lavandula stoechas & $\mathrm{Ca}^{2+}$ antagonists & $0.1-1 \mathrm{mg} / \mathrm{ml}$ & Rabbit intestines & Gilani et al., 2000 \\
\hline \multirow[t]{2}{*}{ Marrubium vulgare } & Likely acts via the NO pathways, & $\begin{array}{l}80 \text { mg dry extract } / \mathrm{kg} \text {, once a } \\
\text { day, for } 5 \text { days. }\end{array}$ & Rat aorta & El Bardai et al., 2001 \\
\hline & Blocks L-type calcium channels & $\begin{array}{l}1-30 \mu \mathrm{M} \text { of marrubenol (a } \\
\text { component of } M \text {. vulgare) }\end{array}$ & Endothelial denuded aortic rings & El-Bardai et al., 2003 \\
\hline Melothria maderaspatana & $\begin{array}{l}\text { Decreases endothelin, } \\
\text { epinephrine and norepinephrine }\end{array}$ & $60 \mathrm{mg} / \mathrm{kg}$ & $\begin{array}{l}\text { DOCA-salt-sensitive hypertensive } \\
\text { rats }\end{array}$ & Veeramani et al., 2012 \\
\hline Microdesmis keayana & Increases eNOS expression & $0.5-50 \mathrm{mg} / \mathrm{ml}$ & Rat and guinea-pig aortic strips & Zamblé et al., 2006 \\
\hline Moldenhawera nutans & Regulates sympathetic tone & $1-10 \mathrm{mg} / \mathrm{kg}$ & Rat isolated aorta & Lahlou et al., 2007 \\
\hline Nitraria sibirica Pall. & Increases NO & $0.1-10 \mathrm{~g} / \mathrm{l}$ & Rat isolated thoracic aortic rings & Senejoux et al., 2012 \\
\hline \multirow[t]{2}{*}{ Ocimum basilicum } & $\begin{array}{l}\text { Ameliorates lipidemia-induced } \\
\text { endothelial dysfunction }\end{array}$ & $0.5 \mathrm{~g} / \mathrm{kg}$ body weight & Rat isolated aortic rings & Amrani et al., 2009 \\
\hline & Decreases ET-1 and Ang II levels & 100,200, and $400 \mathrm{mg} / \mathrm{kg}$ & Renovascular hypertensive rats & Umar et al., 2010 \\
\hline Oenothera odorata & Increases NO & $5.16 \mu \mathrm{g} / \mathrm{ml}$ & Rat carotid arterial rings & Kim et al., 2011 \\
\hline Peganum harmala & Increases NO & $3-30 \mu \mathrm{M}$ & Rat isolated rat aorta & $\begin{array}{l}\text { Shi et al., 2001; Berrougui } \\
\text { et al., } 2006\end{array}$ \\
\hline Petasites formosanus & Antagonizes $\mathrm{Ca}^{2+}$ & $10-100 \mu \mathrm{M}$ & Rat aortic smooth muscles & Wang et al., 2002 \\
\hline $\begin{array}{l}\text { Peucedanum praeruptorum } \\
\text { Dunn }\end{array}$ & Increases NO & $1-100 \mu \mathrm{M}$ & Rat isolated aortic rings & Xu et al., 2010 \\
\hline Piper nigrum & Antagonizes $\mathrm{Ca}^{2+}$ & $1-20 \mu \mathrm{M}$ & Rabbit aortic rings & Taqvi et al., 2008 \\
\hline
\end{tabular}




\section{TABLE 2 | Continued}

\begin{tabular}{|c|c|c|c|c|}
\hline Herb & Effect/Mechanism & Concentration/Dose & Model & References \\
\hline \multirow[t]{2}{*}{ Piper truncatum } & Increases NO & $10.7 \mu \mathrm{g} / \mathrm{ml}$ & Rat aorta & Raimundo et al., 2009 \\
\hline & Regulates histamine receptors & & & \\
\hline Prunella vulgaris & Increases NO & 100 and 200 (mg/kg) & $\mathrm{Db} / \mathrm{db}$ mice with type 2 diabetes & Hwang et al., 2012 \\
\hline $\begin{array}{l}\text { Pseuderanthemum } \\
\text { palatiferum }\end{array}$ & Increases NO & $81 \mu \mathrm{g} / \mathrm{ml}$ & Rat endothelial-intact aortic ring & Khonsung et al., 2011 \\
\hline Pueraria lobata & Opens $K_{\text {ATP }}$ channels & $\begin{array}{l}1 \mathrm{mg} / \mathrm{ml} \text { of the extract; } \\
1-10 \mathrm{nM} \text { of puerarin, a } \\
\text { compound of } P . \text { lobata }\end{array}$ & Rat thoracic aorta & $\begin{array}{l}\text { Sun et al., 2007; Ng et al., } \\
2011\end{array}$ \\
\hline Radix Angelicae & Decreases Ang II levels & $6.25-25 \mathrm{mg} / \mathrm{kg} / \mathrm{day}$ & $2 \mathrm{~K}-1 \mathrm{C}$ rats & Cao et al., 2013 \\
\hline Ranunculus japonicus & Reduces Ang II concentration & $\begin{array}{l}0.2 \mathrm{mg} / \mathrm{ml} \text { (of the plant's } \\
\text { glycosides) }\end{array}$ & $2 \mathrm{~K}-1 \mathrm{C}$ rats & Liu et al., 2012 \\
\hline \multirow[t]{3}{*}{ Raphanus sativus } & Increases NO & 30 and $90 \mathrm{mg} / \mathrm{kg}$ & SHR & Chung et al., 2012 \\
\hline & & $0.3-3 \mathrm{mg} / \mathrm{ml}$ & Rat Isolated aorta & Ghayur and Gilani, 2006 \\
\hline & & & Guinea-pig atria & \\
\hline Rhazya stricta & $\begin{array}{l}\text { Reduces BP and HR; unclear } \\
\text { mechanism }\end{array}$ & 0.5-2 mg/animal & Rats & Tanira et al., 2000 \\
\hline Rhus coriaria & Activates eNOS & $0.3-300 \mu \mathrm{g} / \mathrm{ml}$ & Rabbit isolated aortic rings & Beretta et al., 2009 \\
\hline Sesamum indicum & Increases NO & $180 \mathrm{mg} / \mathrm{ml}$ & Rat Isolated aorta & Suresh Kumar et al., 2008 \\
\hline Solanum sp & Increases NO & $75 \mu \mathrm{g} / \mathrm{ml}$ & Rat aortic rings & Monteiro et al., 2012 \\
\hline Sorbus cortex & Regulates NO and ET-1 & 100 and $200 \mathrm{mg} / \mathrm{kg}$ & Rats with atherogenic diet & Sohn et al., 2005 \\
\hline Stephania tetrandra & Blocks $\mathrm{Ca}^{2+}$ channels & $\begin{array}{l}\text { 3-30 mg/kg (i.v.) or } 10-30 \mu \mathrm{M} \\
\text { of tetrandrine in the } \\
\text { pulmonary artery; }\end{array}$ & Rats & Qian et al., 1983 \\
\hline \multirow[t]{2}{*}{ Tribulus terrestris } & Increases NO & $0.3-15 \mathrm{mg} / \mathrm{ml}$ & SHR & Phillips et al., 2006 \\
\hline & Reduces ACE & $10 \mathrm{mg} / \mathrm{kg}$ & $2 \mathrm{~K}-1 \mathrm{C}$ rats & Sharifi et al., 2003 \\
\hline Tridax procumbens & Not clear & $0.15-1.05 \mathrm{mg} / \mathrm{ml}$ & Rat isolated aortic rings & $\begin{array}{l}\text { Salahdeen and Murtala, } \\
2012\end{array}$ \\
\hline \multirow[t]{2}{*}{ Tropaeolum majus } & Inhibits ACE & $\begin{array}{l}30-300 \mathrm{mg} / \mathrm{kg} \text { of } \\
\text { hydroethanolic extract, or }\end{array}$ & $\begin{array}{l}\text { ACE activity assay (in serum from } \\
\text { normotensive Wistar rats) }\end{array}$ & $\begin{array}{l}\text { Gasparotto Junior et al., } \\
2012\end{array}$ \\
\hline & Increases NO & semi-purified fraction & & \\
\hline Uncariae ramulus et Uncus & Increases NO & 450 mg/kg/day & SHR & Goto et al., 1999 \\
\hline \multirow[t]{2}{*}{ Viola odorata } & Increases NO & 0.39 and $0.4 \mathrm{mg} / \mathrm{ml}$ & Guinea-pig atria and rat aorta & Siddiqi et al., 2012 \\
\hline & Regulates $\mathrm{Ca}^{2+}$ & $0.3-3 \mathrm{mg} / \mathrm{ml}$ & & \\
\hline Viscum articulatum Burm & Increases NO & $60 \mathrm{mg} / \mathrm{kg} /$ day & Glucocorticoid-treated rats & Bachhav et al., 2011 \\
\hline Zizyphi Spinosi & Increases NO & $0.1-100 \mu \mathrm{M}$ & L-NAME treated rats & Fu et al., 2011 \\
\hline
\end{tabular}


TABLE 3 | Less commonly used antihypertensive plants with anti-inflammatory activity.

\begin{tabular}{|c|c|c|c|c|}
\hline Herb & Effect/Mechanism & Concentration/Dose & Model & References \\
\hline Arctium lappa & Suppresses VCAM-1 (aortic endothelia) & 100 and $200 \mathrm{mg} / \mathrm{kg} /$ day & $\begin{array}{l}\text { High fat-fed Sprague-Dawley rat } \\
\text { thoracic aorta }\end{array}$ & Lee Y. J. et al., 2012 \\
\hline Carthamus tinctorius & Decreases soluble (plasma) VCAM-1 & $2.1 \mathrm{~g} /$ day & Healthy humans & Koyama et al., 2009 \\
\hline Cirsium japonicum & $\begin{array}{l}\text { Decreases NF-кB expression (mast } \\
\text { cells) }\end{array}$ & $0.05-0.4 \mathrm{mg} / \mathrm{ml}$ & HMC-1 human mast cells & Kim et al., 2013 \\
\hline Cuminum cyminum & Decreases TNF- $\alpha$ and IL-6 (renal tissue) & $200 \mathrm{mg} / \mathrm{kg}$ & renovascular hypertensive rats & Kalaivani et al., 2013 \\
\hline Cynanchum wilfordii & $\begin{array}{l}\text { Inhibits VCAM- } 1 \text { and ET-1 activity } \\
\text { (aortic endothelia) }\end{array}$ & 100 and $200 \mathrm{mg} / \mathrm{kg} /$ day & $\begin{array}{l}\text { High fat/cholesterol-fed } \\
\text { ApoE-deficient mice }\end{array}$ & Choi et al., 2012b \\
\hline Gastrodia elata Blume & $\begin{array}{l}\text { Decreases iNOS expression (gastric } \\
\text { mucosa) }\end{array}$ & $0.02 \mathrm{~mL} / \mathrm{g}$ & Stress-induced gastric lesions in mice & An et al., 2007 \\
\hline Phyllanthus amarus & $\begin{array}{l}\text { Decreases NF-кB, TNF- } \alpha \text {, and COX-2 } \\
\text { (RAW } 264.7 \text { cells) }\end{array}$ & $\begin{array}{l}0-250 \mu \mathrm{g} / \mathrm{ml} \text { (aqueous ethanol) } \\
\text { or } 0-200 \mu \mathrm{g} / \mathrm{ml} \text { (hexane) } \\
\text { fractions }\end{array}$ & $\begin{array}{l}\text { LPS-treated RAW } 264.7 \\
\text { macrophages }\end{array}$ & Kiemer et al., 2003 \\
\hline Pueraria lobata & $\begin{array}{l}\text { Decreases expression of iNOS (RAW } \\
264.7 \text { cells) }\end{array}$ & $\begin{array}{l}20 \text { and } 100 \mu \mathrm{M} \text { of lupenone or } \\
\text { lupeol, respectively }\end{array}$ & $\begin{array}{l}\text { LPS-treated RAW } 264.7 \\
\text { macrophages }\end{array}$ & Jin et al., 2012 \\
\hline Radix Astragali & $\begin{array}{l}\text { Attenuates IFN- } \gamma \text { and IL-2 (serum of } \\
\text { rats) }\end{array}$ & $\begin{array}{l}0.4 \mathrm{~g} \text { of the plant per } 100 \mathrm{~g} \text { of } \\
\text { the animal weight }\end{array}$ & Rat model of autoimmune myocarditis & Zhao et al., 2008 \\
\hline Raphanus sativus & $\begin{array}{l}\text { Reduces LPS-induced NO, IL-1 } \beta \text {, } \\
\text { TNF- } \alpha \text {, and IFN- } \gamma \text { (RAW } 264.7 \text { cells) }\end{array}$ & $100 \mu \mathrm{g} / \mathrm{ml}$ of each sub-fraction & $\begin{array}{l}\text { LPS-stimulated } \\
\text { RAW264.7macrophages }\end{array}$ & Kook et al., 2014 \\
\hline Rheum rhabarbarum & $\begin{array}{l}\text { Reduces LPS-induced NO, IL- } 6, \mathrm{IL}-1 \beta \text {, } \\
\text { IL-8, or TNF- } \alpha \text { (colon tissue or RAW } \\
264.7 \text { cells) }\end{array}$ & $\begin{array}{l}100 \mathrm{mg} / \mathrm{kg} \text { rhein (in mice) or } \\
8-40 \mu \mathrm{M} \text { of different } \\
\text { anthraquinones (in RAW264.7 } \\
\text { cells) }\end{array}$ & Mice or RAW264.7 cells & $\begin{array}{l}\text { Hu et al., 2014; } \\
\text { Zhang et al., } 2015\end{array}$ \\
\hline Sophora flavescens Ait & $\begin{array}{l}\text { Reduces expression of IL-6, VCAM-1, } \\
\text { and ET-1 (pulmonary artery endothelia) }\end{array}$ & $0.5-2 \mathrm{mg} / \mathrm{mL}$ & $\begin{array}{l}\text { Monocrotaline-induced pulmonary } \\
\text { hypertension in rats }\end{array}$ & Zhang et al., 2014 \\
\hline Sorbus cortex & $\begin{array}{l}\text { Regulates NO and ET-1 (aortic } \\
\text { endothelia) }\end{array}$ & 100 and $200 \mathrm{mg} / \mathrm{kg}$ & Rats with atherogenic diet & Sohn et al., 2005 \\
\hline \multirow[t]{2}{*}{ Stephania tetrandra } & $\begin{array}{l}\text { Inhibits LPS-induced expression of } \\
\mathrm{PgE}_{2} \text {, iNOS, and COX-2 (THP-1 } \\
\text { monocytic cell line) }\end{array}$ & $\begin{array}{l}100 \mu \mathrm{M} \text { of tetrandrine }(\mathrm{a} \\
\text { component of } S . \text { tetrandra) }\end{array}$ & THP-1 cells & Wu and Ng, 2007 \\
\hline & $\begin{array}{l}\text { Reduces LPS-induced levels of IL1 } \beta \\
\text { and TNF } \alpha \text { (BV-2 microglia) }\end{array}$ & $\begin{array}{l}0.1-1 \mu \mathrm{M} \text { of tetrandrine (a } \\
\text { component of } S \text {. tetrandra) }\end{array}$ & BV-2 microglia & Dang et al., 2014 \\
\hline
\end{tabular}

et al., 2009; Table 3). Additional evidence supports the regulatory effect of safflower on vascular tone in hypertensive rabbits (Di and Chang, 2007). Furthermore, two major indolic polyphenols in safflower seeds, namely $\mathrm{N}$-(p-coumaroyl)serotonin (CS) and $\mathrm{N}$-feruloylserotonin (FS), were shown to relax rat femoral arteries in an endothelium-independent manner (Takimoto et al., 2011). They also inhibited PDGF-induced proliferation of VSMCs (Takimoto et al., 2011).These data suggest a hypotensive effect of $C$. tinctorius $L$. that warrants further investigation. However, in a double-blind, placebo-controlled clinical trial, ingestion of ethanolic safflower extract (70 mg/day; for 12 weeks) caused a marginal yet not significant decrease in SBP or DBP (Suzuki et al., 2010). The study reported, however, that arterial stiffness and vascular aging were ameliorated (Suzuki et al., 2010; Table 6).

\section{Cassia occidentalis (Reclassified as Senna Occidentalis) (Coffee Weed)}

Coffee weed (common name) has been found to lower BP level (Ajagbonna et al., 2001), possibly due to inhibition of external $\mathrm{Ca}^{2+}$ influx via voltage-dependent channels (Ajagbonna et al., 2001; Table 2). In addition, aqueous extracts of the plant leaves (3.07 and $3.63 \mathrm{mg} / \mathrm{ml}$ ) control vascular tone in rat aortic rings by mechanisms that were not affected by endothelium-denudation, indomethacin, or methylene blue (Ajagbonna et al., 2001). The aforementioned anti-hypertensive effects may be facilitated 
TABLE 4 | Less commonly used antihypertensive plants with antiproliferative activity.

\begin{tabular}{|c|c|c|c|c|}
\hline Herb & Effect/Mechanism & Concentration/Dose & Model & References \\
\hline $\begin{array}{l}\text { Angelica sinensis and } \\
\text { Ligusticum chuanxiong }\end{array}$ & Arrests VSMCs at G0/G1 & $300 \mu \mathrm{g} / \mathrm{ml}$ & Rat vascular smooth muscles & Hou et al., 2005 \\
\hline Raphanus sativus & Arrests VSMCs in G1 phase & $20-160 \mu \mathrm{g} / \mathrm{ml}$ & Mouse aortic smooth muscle cells & Suh et al., 2006 \\
\hline Sophora flavescens Ait & $\begin{array}{l}\text { Inhibits hypoxia or TGF- } \beta \text {-induced } \\
\text { proliferation }\end{array}$ & $0.5-0.2 \mathrm{mg} / \mathrm{ml}$ & $\begin{array}{l}\text { Pulmonary arterial smooth muscle } \\
\text { cells }\end{array}$ & Zhang et al., 2014 \\
\hline Tribulus terrestris & Inhibits Ang II-induced proliferation & $\begin{array}{l}0.240 \mathrm{mg} / \mathrm{ml} \text { of the } \\
\text { plant's total saponins }\end{array}$ & $\begin{array}{l}\text { Primary VSMCs from aorta of } \\
\text { newborn calves }\end{array}$ & Li et al., 2013 \\
\hline
\end{tabular}

TABLE 5 | Less commonly used antihypertensive plants with diuretic activity.

\begin{tabular}{|c|c|c|c|c|}
\hline Herb & Effect/Mechanism & Concentration/Dose & Model & References \\
\hline Elettaria cardamomum & $\begin{array}{l}\text { Increases urine output and enhances } \\
\mathrm{Na}^{+} \text {and } \mathrm{K}^{+} \text {excretion }\end{array}$ & 1,3 , and $10 \mathrm{mg} / \mathrm{kg}$ & Anesthetized rats & Gilani et al., 2008 \\
\hline Lepidium latfolium & $\begin{array}{l}\text { Increases urine output and electrolyte } \\
\text { excretion }\end{array}$ & $50-100 \mathrm{mg} / \mathrm{kg}$ & Rats & Navarro et al., 1994 \\
\hline Lepidium sativum & Increases electrolyte excretion & $20 \mathrm{mg} / \mathrm{kg}$ & SHR & Maghrani et al., 2005 \\
\hline Phyllanthus amarus & $\begin{array}{l}\text { Increases urine volume and } \mathrm{Na}^{+} \\
\text {levels in serum (humans) and } \\
\text { decreases SBP and DBP (in man) }\end{array}$ & 80 mg/kg (in rabbits) & $\begin{array}{l}\text { Mild hypertensive patients } \\
\text { and rabbits }\end{array}$ & $\begin{array}{l}\text { Srividya and Periwal, } \\
\text { 1995; Amaechina and } \\
\text { Omogbai, } 2007\end{array}$ \\
\hline \multirow[t]{3}{*}{ Tropaeolum majus $L$} & Reduces aldosterone & $\begin{array}{l}300 \mathrm{mg} / \mathrm{kg} \text { ethanolic extract, } 200 \mathrm{mg} / \mathrm{kg} \\
\text { purified fraction, } 10 \mathrm{mg} / \mathrm{kg} \text { isoquercitrin }\end{array}$ & SHR & $\begin{array}{l}\text { Gasparotto Junior } \\
\text { et al., } 2012\end{array}$ \\
\hline & Downregulates renal $\mathrm{Na}^{+} / \mathrm{K}^{+}$pump & & & \\
\hline & Increases urine volume & & & \\
\hline \multirow[t]{2}{*}{ Viscum articulatum Burm } & Increases urine volume & 200 mg/kg/day & L-NAME-treated rats & Bachhav et al., 2012 \\
\hline & $\begin{array}{l}\text { Increases urine volume, electrolyte } \\
\text { excretion and glomerular filtration rate }\end{array}$ & 100,200, and $400 \mathrm{mg} / \mathrm{kg}$ & Male Wistar rats & Jadhav et al., 2010 \\
\hline
\end{tabular}

by other synergistic actions of $C$. occidentalis. For instance, coffee weed leaves possess anti-inflammatory and anti-oxidant properties, evident by their ability to reduce lipid peroxide content and suppress activity of phospholipase $A_{2}$ (Yadav et al., 2010). Recently, it was also shown that the aqueous extract of this plant has a diuretic effect and improves kidney function indices in rats (Ntchapda et al., 2015).

\section{Cinnamomum zeylanicum (Cinnamon)}

Cinnamon is a known functional food. It has been reported to produce a blood lowering effect in several rat models (Nyadjeu et al., 2011, 2013; Table 2) as well as in type 2 diabetic and pre-diabetic humans (Akilen et al., 2013). The aqueous extract of its stem bark has been shown to reduce sucrose-induced elevation in SBP of SHRs (Preuss et al., 2006) as well as inhibit contractions induced by $\mathrm{KCl}$ in rat isolated aortic rings (Nyadjeu et al., 2011). This latter effect was dependent on the endothelium, $\mathrm{NO}$, and $\mathrm{K}_{\mathrm{ATP}}$ channels (Nyadjeu et al., 2011). Interestingly, the methanolic extract of the bark $(300 \mathrm{mg} / \mathrm{kg} /$ day for 4 weeks) has also been shown to increase levels of NO in L-NAME-induced hypertension in rats (Nyadjeu et al., 2013). These data suggest a NO-dependent mechanism for the antihypertensive effects of C. zeylanicum. Importantly, during the revision of this manuscript, Azimi et al. published the results of a parallel randomized placebocontrolled clinical trial showing that consumption of cinnamon does not affect BP in type II diabetic patients (Azimi et al., 2016). However, this study suffered from many limitations including the short duration and small amount of cinnamon consumed, in addition to the fact that the sample participants were relatively old.

\section{Cirsium japonicum (Japanese Thistle)}

Cirsium japonicum is a perennial herb that is typically found in China, Korea and Japan, and it belongs to the family Compositae. This Japanese thistle (common name) was suggested to be have an antihypertensive value (Kim et al., 2013). Its aqueous extract $(0.1-1.0 \mathrm{mg} / \mathrm{ml})$ has been reported to induce vasorelaxation 
TABLE 6 | Less commonly used antihypertensive plants used in clinical trials.

\begin{tabular}{|c|c|c|c|c|c|c|c|c|}
\hline Herb & Design & $\begin{array}{l}\text { Population } \\
\text { Size }\end{array}$ & Condition & Dose & Duration & Effect & $\begin{array}{l}\text { Magnitude of } \\
\text { change }\end{array}$ & References \\
\hline $\begin{array}{l}\text { Carthamus } \\
\text { tinctorius L }\end{array}$ & $\begin{array}{l}\text { Double-blind, } \\
\text { placebo-controlled }\end{array}$ & 92 & $\begin{array}{l}\text { Mild } \\
\text { hypertension }\end{array}$ & $\begin{array}{l}70 \text { mg/day ethanolic } \\
\text { safflower extract }\end{array}$ & 12 weeks & $\begin{array}{l}\text { No significant } \\
\text { SBP or DBP } \\
\text { decrease }\end{array}$ & $0.8 / 1 \mathrm{mmHg}$ & $\begin{array}{l}\text { Suzuki } \\
\text { et al., } 2010\end{array}$ \\
\hline $\begin{array}{l}\text { Elettaria } \\
\text { cardamomum }\end{array}$ & $\begin{array}{l}\text { Placebo-controlled } \\
\text { trial }\end{array}$ & 20 & $\begin{array}{l}\text { Stage } 1 \\
\text { hypertension }\end{array}$ & $\begin{array}{l}3 \mathrm{~g} \text { cardamom powder } \\
\text { (1.5 g capsule, twice a } \\
\text { day) }\end{array}$ & 12 weeks & $\begin{array}{l}\text { SBP and DBP } \\
\text { decrease }\end{array}$ & 19/12 mmHg & $\begin{array}{l}\text { Verma } \\
\text { et al., } 2009\end{array}$ \\
\hline $\begin{array}{l}\text { Melothria } \\
\text { maderaspatana }\end{array}$ & Controlled trial & 50 & $\begin{array}{l}\text { Mild } \\
\text { hypertension }\end{array}$ & $4 \%$ tea leaf powder & 45 days & $\begin{array}{l}\text { SBP and DBP } \\
\text { decrease }\end{array}$ & 23.8/15.5 mmHg & $\begin{array}{l}\text { Raja et al., } \\
2007\end{array}$ \\
\hline
\end{tabular}

of noradrenaline $(0.3 \mu \mathrm{M})$ pre-constricted rat isolated thoracic aortic rings through activation of histamine $\mathrm{H} 1$ receptors (Kim et al., 2008). The underlying mechanism involves elevated levels of NO and cGMP (Kim et al., 2008; Table 2).

Thistles have also been used for the treatment of inflamed venular system, indicative of anti-inflammatory properties. Indeed, silibinin $(0.05-0.4 \mathrm{mg} / \mathrm{ml})$, a polyphenolic constituent of C. japonicum, inhibited the expression and release of inflammatory cytokines (TNF- $\alpha$, IL-6, and IL-8), and decreased the NF- $\kappa \mathrm{B}$ transcriptional capacity via diminishing the phosphorylation of I $\mathrm{B} \alpha$ (Kim et al., 2013; Table 3). More recently, silibinin was found to be an antagonist for the human angiotensin $\mathrm{AT}_{1}$ receptor (Bahem et al., 2015). This may provide a potential explanation for the observation that silibinin reduced SBP in L-NAME-treated rats (Souza et al., 2012).

\section{Coleus forskohlii (Makandi)}

Also known as Makandi, the Coleus forskohlii plant is central to Ayurvedic herbal remedies. This plant is famous for its isolate, forskolin, or coleonol (labdane diterpenoid), which is a potent adenylyl cyclase activator. Forskolin increases intracellular levels of cAMP leading to activation of protein kinase A (PKA, or cAMP-dependent protein kinase), which in turn induces relaxation of vascular smooth muscle cells (Lindner et al., 1978; Tirapelli et al., 2010; Table 2). Therefore, it is not surprising that forskolin has been reported for its BP lowering activity in cats (Dubey et al., 1981), rats (Dubey et al., 1981) including SHRs (Dubey et al., 1981), and humans (Dubey et al., 1981; Tirapelli et al., 2010; Table 2).

\section{Cynanchum wilfordii (Dog-strangling Vine)}

C. wilfordii ethanolic extracts (100 and $200 \mathrm{mg} / \mathrm{kg} /$ day) are known to reduce BP in high fat/cholesterol-fed rats (Choi et al., 2012a; Table 2). This extract acts by activating Akt, leading to an enhanced eNOS activity, and release of increased levels of NO (Choi et al., 2012a). In ApoE-deficient mice on a high fat/cholesterol diet, C. wilfordii mitigated aortic endothelial dysfunction (Choi et al., 2012b). This was dependent on augmented NO and cGMP production, as well as decreased the expression of VCAM-1 and ET-1 (Choi et al., 2012b; Tables 2, 3). Indeed, it was previously shown that C. wilfordii induces endothelium-dependent and cGMP-mediated relaxation of rat aorta (Choi et al., 2010). These results suggest a robust hypotensive response of $C$. willfordii in experimental rodent models.

\section{Echinodorus grandiflorus (Burhead)}

Echinodorus grandiflorus (Cham. \& Schltdl.) Micheli is a semiaquatic plant that is native to Brazil. This plant belongs to the Alismataceae family. Evidence suggests that the aqueous extracts of this plant have the ability to reduce MAP as well as cardiac output and vascular resistance in SHRs (Lessa et al., 2008; Table 2). The crude extract has also been reported to induce relaxation of endothelium-intact rabbit isolated aortic rings (Tibiriçá et al., 2007); these effects were reversed when NO production was inhibited (Tibiriçá et al., 2007; Lessa et al., 2008). This implies that E. grandiflorus's cardioprotective, vasorelaxant and hypotensive effects are modulated by an NO-dependent mechanism. While this manuscript was being reviewed, Prando et al. reported that the ethanolic extract of E. grandiflorus causes a hypotensive as well as antihypertensive effect in a renovascular rat model of hypertension, twokidney-one-clip (2K-1C; Prando et al., 2015). These two effects appear to be modulated by bradykinin $\mathrm{B}_{2}$ and muscarinic receptors as well as NO and cyclooxygenases (Prando et al., 2015).

\section{Elettaria cardamomum (Cardamom)}

Elettaria cardamomum is commonly known as cardamom. In powder form $(3 \mathrm{~g})$, it decreases mean arterial blood pressure (MAP), as well as SBP and DBP in pre-hypertensive (Stage 1) subjects (Verma et al., 2009; Table 6). SBP and DBP were significantly decreased by 19 and $12 \mathrm{mmHg}$, respectively (Verma et al., 2009).The mechanism for this hypotensive action appears to be due to cardamom's ability to increase the total antioxidant status (Verma et al., 2009; Table 1). In anesthetized rats, 3$100 \mathrm{mg} / \mathrm{kg}$ of E. cardamomum crude extract was also able to reduce BP (Gilani et al., 2008). In the same model, $1-10 \mathrm{mg} / \mathrm{kg}$ of the crude extract exhibited diuretic effects (Gilani et al., 2008; Table 5). It also relaxed pre-constricted rat aortic rings with a concentration of $2.94 \mathrm{mg} / \mathrm{ml}$, possibly by inhibiting $\mathrm{Ca}^{2+}$ movement through transmembrane calcium channels (Gilani et al., 2008; Table 2). Interestingly, during the revision of this manuscript, Azimi et al. reported that they failed to find any 
appreciable effect of cardamom or BP in type II diabetic patients (Azimi et al., 2016).

\section{Embelia ribes}

Embelia ribes has been reported to produce different hypotensive effects. In isoproterenol-treated rats, the aqueous extract of $E$. ribes $(100 \mathrm{mg} / \mathrm{kg})$ was able to decrease both the SBP and heart rate, as well as increase endogenous antioxidants such as SOD, CAT, and GSH (Bhandari et al., 2008a,b) (Table 1). Similar results were produced after treatment of high fat-fed rats with $50 \mathrm{mg} / \mathrm{kg}$ of embelin, a bioactive component of the herb (Chaudhari et al., 2012; Table 1).

\section{Gastrodia elata Blume (Tianma)}

Gastrodia rhizome has been reported to possess antihypertensive effects (Lee O. H. et al., 2012). Treatment of high fat-fed SHR with acidic polysaccharides isolated from the rhizome $(6 \mathrm{mg} / \mathrm{kg}$ of body weight/day for 5 weeks) caused a significant reduction in BP level (Lee O. H. et al., 2012). In the same study, a decrease in the concentration of total cholesterol, LDL-cholesterol, and triglycerides in serum were also noted (Lee O. H. et al., 2012; Table 1). In addition, the methanolic extracts $(0.02 \mathrm{ml} / \mathrm{g})$ of Gastrodia rhizome showed anti-inflammatory effects by reducing iNOS expression, and thereby decreasing the level of NO (An et al., 2007; Table 3). There are other reports that show the beneficial cardiovascular effects of gastrodin, a major bioactive component of Gastordia elata Bl. For example, injection of gastrodin into elderly patients with refractory hypertension caused a decrease in systolic and pulse pressures (Zhang et al., 2008). Furthermore, this study showed that gastrodin increase NO levels while it simultaneously reduced endothelin levels (Zhang et al., 2008). Recently, the underlying mechanism for gastrodin's effects was elucidated. Liu et al. showed that gastrodin lower SBP by interfering with the Renin-AngiotensinAldosterone system (RAAS) (for further explanation on the role of RAAS, please refer to Part I of this review Al Disi et al., 2015). Indeed, gastrodin decreased serum levels of Ang II as well as expression of both of $\mathrm{ACE}$ and $\mathrm{AT}_{1} \mathrm{R}$ (Liu W. et al., 2015).

\section{Gentiana floribunda}

Recently, Gentiana floribunda's BP lowering effect was reported (Khan et al., 2012; Table 2). It relaxed the aorta of rats in a dose-dependent manner $(0.3-1 \mathrm{mg} / \mathrm{ml})$, possibly by blocking $\mathrm{Ca}^{2+}$ channels (Khan et al., 2012). L-NAME did not affect $G$. floribunda's activity, indicative of a NO-independent mechanism (Khan et al., 2012).

\section{Gossypium barbadense (Pima Cotton)}

Commonly known as pima cotton, G. barbadense induces relaxation of guinea pig aorta, which may offer an explanation for its observed lowering effect on BP (Hasrat et al., 2004; Tabassum and Ahmad, 2011).

\section{Gynura procumbens (Pointed Phoenix Tail)}

The aqueous extract of Gynura procumbens has been reported to produce blood-pressure-lowering effect in SHRs (Kim et al., 2006; Hoe et al., 2007) and in WKY (Hoe et al., 2007;
Table 2). It can also inhibit Ang I- and Ang II-induced contractions in rat aortic rings via a NO-dependent mechanism (Poh et al., 2013). This result is in agreement with other reports showing the ability of $500 \mathrm{mg} / \mathrm{kg}$ of G. procumbens extract to increase levels of NO in SHRs (Kim et al., 2006). The aqueous extract has also been reported to inhibit ACE activity (Poh et al., 2013). Furthermore, a partially purified fraction of $G$. procumbens inhibited Ang I-induced elevation in MAP, apparently via inhibiting ACE activity (Hoe et al., 2007).

The crude extract $(0.003$ and $0.009 \mathrm{~g} / \mathrm{ml})$ also exhibited vasodilatory effect, as it inhibited both $\mathrm{KCl}$ - and phenylephrineinduced contractions in rat isolated thoracic aortic rings $(\mathrm{Ng}$ et al., 2013). This vasorelaxant function is related to the opening of potassium channels, inhibition of calcium channels and release of prostacyclin ( $\mathrm{Ng}$ et al., 2013). All these findings allude to the beneficial role of $G$. procumbens as a hypotensive agent.

\section{Kaempferia parviflora (Thai or Black Ginseng)}

Not only can Kaempferia parviflora, or black ginseng, inhibit phenylephrine-induced contraction of rat isolated aortic rings (Wattanapitayakul et al., 2008), but it can also induce their relaxation (Tep-Areenan et al., 2010; Table 2). This relaxation is due to $K$. parviflora's bioactive component, 5,7dimethoxyflavone $(1-100 \mu \mathrm{M})$, which augmented NO and cGMP levels (Tep-Areenan et al., 2010). The same study reported that 10 and $100 \mu \mathrm{M}$ of 5,7-dimethoxyflavone exerts vasorelaxant effects by reducing extracellular $\mathrm{Ca}^{2+}$ influx (Tep-Areenan et al., 2010). The same vasorelaxant mechanisms were also reported for this herb in rat hearts and ventricular myocytes (Weerateerangkul et al., 2012; Table 2).

It is important to note that other mechanisms may also contribute to black ginseng's antihypertensive potential. For example, this plant was shown to potently reduce oxidative stress in aortae of diabetic rats (Malakul et al., 2011). This is in line with a more recent report showing that extracts of K. parviflora ameliorate endothelial dysfunction by reducing oxidative stress and increasing eNOS in human endothelial cells (Wattanapitayakul et al., 2007; Horigome et al., 2015). These extracts also inhibited adhesion of monocytes to endothelial cells as well as reduced levels of pro-inflammatory cytokines (Horigome et al., 2015).

\section{Lavandula stoechas (Lavender)}

French lavender extracts cause decreases in heart rate and $\mathrm{BP}$ in rats (Tabassum and Ahmad, 2011). They were also reported to relax rabbit intestines $(0.1-1 \mathrm{mg} / \mathrm{ml})$, possibly by $\mathrm{Ca}^{2+}$ channel inhibition (Gilani et al., 2000; Table 2). This relaxant activity on intestines' smooth muscles could indicate hypotensive effect if confirmed on VSMCs or endothelial cells. However, it remains to be determined. Constituents of the Lavendula genus are known to reduce inflammatory stress through different mechanisms such as scavenging free radical, promoting antioxidants levels, and reducing the concentration of arachidonic acid metabolites (Sosa et al., 2005). 


\section{Lepidium}

A hypotensive effect of Lepidium sativum (garden cress; $20 \mathrm{mg} / \mathrm{kg}$ ) has been reported in SHR but not WKY rats (Maghrani et al., 2005). This effect appears to be related to the increased urinary elimination of sodium, potassium, and chlorides (Maghrani et al., 2005; Table 5). Recently, two new glycosides isolated from seeds of $L$. sativum were shown to have an anti-inflammatory potential (Fan et al., 2014). Another member of the Lepidium genus is Lepidium latifolium, commonly known as broadleaved pepper weed. This plant has been shown to induce diuresis (Navarro et al., 1994), an effect that has been observed in both rats and man (Navarro et al., 1994; Wright et al., 2007; Table 5). Moreover, Lepidium latifolium displays a potent antioxidant capacity, which may contribute to its antihypertensive effects (Kaur et al., 2013; Table 1).

\section{Marrubium vulgare (White Horehound)}

White horehound is reported to significantly decrease SBP in SHRs (El Bardai et al., 2001, 2004; Table 2). This hypotensive effect is probably due to its vasorelaxant and anti-hypertrophic activities. White horehound was found to relax rat aorta (El Bardai et al., 2001), potentiate acetylcholine (ACh)-induced relaxation of mesenteric artery (El Bardai et al., 2004; Table 2), and elicit an antihypertrophic effect in aorta (El Bardai et al., 2004). Importantly, this plant can also ameliorate the impaired endothelial function in SHRs (El Bardai et al., 2004). The mechanism of action is not yet completely understood, but it appears to be NO-independent as L-NAME did not affect horehound's vasodilatory action (El Bardai et al., 2001).

Different molecules isolated from white horehound seem to contribute to these vasculoprotective effects. For example, the diterpene marrubenol can potently block L-type calcium channels and consequently inhibit contraction of VSMCs (El-Bardai et al., 2003). Both marrubenol and marrubiin, another diterpene from Marrubium vulgare inhibit $\mathrm{KCl}$-induced contractions of rat aorta (El Bardai et al., 2003). Furthermore, phenylpropanoids isolated from this plant can also inhibit lipoprotein-induced secretion of the potent vasoconstrictor endothelin-1 (Martin-Nizard et al., 2004).

\section{Melothria maderaspatana (Melon-Gubat)}

M. maderaspatana has been reported to diminish BP in DOCAsalt hypertensive rats (Veeramani et al., 2011, 2012; Table 2) as well as in hypertensive humans (Raja et al., 2007). Indeed, individuals with mild hypertension that consumed melon-gubat tea $(4 \% \mathrm{w} / \mathrm{v}$ leaf powder) for 45 days showed a significant decrease in both SBP and DBP (23.8 and $15.5 \mathrm{~mm} \mathrm{Hg}$, respectively) (Raja et al., 2007; Table 6). It has also shown a positive effect on eNOS (Veeramani et al., 2012) and cellular antioxidants (Veeramani et al., 2011) levels in DOCA-salt induced hypertension (Table 1). Importantly, M. maderaspatana seems to decrease levels of ET-1, epinephrine and norepinephrine (Veeramani et al., 2012).

\section{Ocimum basilicum (Sweet Basil)}

Sweet basil's crude extract dose-dependently (100-400 mg/kg) decreased BP level in rats (Umar et al., 2010), as well as inhibited renovascular hypertension-induced hypertrophy of heart and increase in ET-1 and Ang II levels (Umar et al., 2010; Table 2). It was also reported to cause a vasorelaxant effect in rat aortic rings, though the mechanism for this relaxation was not determined (Amrani et al., 2009; Table 2). Perhaps one potential mechanism could be due to the sweet basil's potent ROS scavenging ability (Kaurinovic et al., 2011; Table 1).

\section{Peganum harmala (Esfand)}

Peganum harmala is commonly known as Esfand and is used in some cultures for the treatment of hypertension (Tahraoui et al., 2007). Not only does P. harmala inhibit the contraction of rat isolated aorta (Astulla et al., 2008), but it also induces relaxation via both endothelial cells and VSMCs (Shi et al., 2001; Astulla et al., 2008; Table 2). Interestingly, Berrougui et al. report that the vasorelaxant effect of $P$. harmala seeds' methanolic extract is endothelium-independent (Berrougui et al., 2002). Esfand's active components-harmine, harmaline, and harmalol $(3-30 \mu \mathrm{M})$ - exert a vasodilatory effect that is thought to be a result of its ability to increase NO production (Shi et al., 2001; Berrougui et al., 2006; Table 2). The Quinazoline alkaloid, vasicinone, isolated from seeds of Esfand is also reported to induce vasorelaxation in phenylephrine-contracted rat aorta (Astulla et al., 2008).

\section{Phyllanthus amarus (Stonebreaker; Seed-Under-Leaf)}

The stonebreaker is reported to decrease BP in rabbits (Amaechina and Omogbai, 2007) and humans (Srividya and Periwal, 1995). This antihypertensive effect is likely related to its diuretic, antioxidant, and anti-inflammatory activities (Kassuya et al., 2005; Maity et al., 2013; Tables 1, 3, 5). In a clinical trial, $P$. amarus increased urinary output as well as levels of $\mathrm{Na}^{+}$in urine (Srividya and Periwal, 1995). These actions were without any noticeable harmful side effects in the mild hypertensive subjects of the study (Srividya and Periwal, 1995). In addition, the aqueous extract of $P$. amarus $(200 \mathrm{mg} / \mathrm{kg}$ ) was shown to increase plasma antioxidants (GSH, GPx, SOD, and CAT) in rats (Karuna et al., 2009; Table 1). Furthermore, different solvent extracts of $P$. amarus have been reported to inhibit of NF- $\kappa$, TNF- $\alpha$, and COX-2 in LPS-treated RAW 264.7 macrophages (Kiemer et al., 2003; Table 3).

\section{Pueraria lobata (Kudzu)}

Pueraria lobata's, or gegen's, isoflavones are reported to decrease BP in dogs and in hypertensive patients (Tabassum and Ahmad, 2011). This is possibly due to gegen's vasodilatory effect, which could be a result of its ability to activate calciumactivated potassium channels in rat thoracic aorta (Sun et al., 2007; Ng et al., 2011; Table 2). However, when combined with Salvia miltiorrhiza, $P$. lobata offered cardiovascular protective effects in high-risk hypertensive patients (Woo et al., 2013). This adjunctive treatment was able to improve endothelium-dependent vasodilation as well as decrease carotid intima-to-media thickness (Woo et al., 2013). P. lobata's antiinflammatory and anti-oxidant activities may partly explain the anti-hypertensive effects of this plant (Jin et al., 2012; Tables 1, 3). 
Puerarin [7-hydroxy-3-(4-hydroxyphenyl)-1-benzopyran-4one 8 -( $\beta$-D-glucopyranoside)] is the major bioactive compound isolated from kudzu. It is reported that puerarin possesses antihypertensive and other cardioprotective effects (Song et al., 1988; Li et al., 2008). Moreover, puerarin could be beneficial in the management of hypoxia-induced pulmonary hypertension (Chen et al., 2011, 2012; Zhang et al., 2011).

\section{Raphanus sativus (Radish)}

Extracts of seeds or leaves of radish have been reported to induce BP-lowering effect in rats. In SHRs, leave extracts (30 and $90 \mathrm{mg} / \mathrm{kg}$ ) reduced SBP (Chung et al., 2012), while the seeds $(0.1-3 \mathrm{mg} / \mathrm{kg})$ lowered $\mathrm{BP}$ as well as the heart rate (Ghayur and Gilani, 2006; Table 2). In SHRs, radish extracts were also reported to enhance NO production and increase antioxidant levels (Chung et al., 2012; Table 1). The seed extract $(0.3-3 \mathrm{mg} / \mathrm{ml})$ exhibited vasorelaxant effects, and was able to inhibit contraction of rat aorta as well as atria of guinea pigs (Ghayur and Gilani, 2006). These vasorelaxant effects of radish are thought to be mediated by NO production (Ghayur and Gilani, 2006). In addition, both methanolic and acetone extracts of radish were able to scavenge ROS in an enzymatic assay (Beevi et al., 2010). The anti-proliferative and anti-inflammatory capacities of radish may also be partial contributors to its overall antihypertensive effects. Indeed, radishes can inhibit proliferation of VSMCs and arrest them in G1 phase of the cell cycle (Suh et al., 2006; Table 4). Radish can also inhibit LPSinduced pro-inflammatory molecules such as NO, IL-1 $\beta$, TNF$\alpha$, and IFN- $\gamma$ (Kook et al., 2014; Table 3). Recently, it was also shown that phenylpropanoid sucrosides isolated from seeds of radish can also inhibit LPS-induced inflammation in murine BV-2 microglial cells (Kim et al., 2015). For more details on role of inflammation or VSMC proliferation in hypertension, part I of this review could be referred to (Al Disi et al., 2015).

\section{Rhazya stricta (Harmal)}

Rhazya stricta's leaves have been documented to lower BP in rats (Tanira et al., 2000; Table 2). In addition, Tanira et al. reported that $R$. stricta induced relaxation in guinea pig and rabbit small intestines (Tanira et al., 1996).

\section{Rhus coriaria (Sumac)}

Rhus coriaria, commonly known as sumac, is known for its antioxidant activity (Candan and Sokmen, 2004; Kosar et al., 2007; Pourahmad et al., 2010; Table 1). Extracts of this plant's leaves have been shown to cause relaxation of isolated rabbit aorta rings pre-contracted with norepinephrine (Beretta et al., 2009; Table 2). This vasorelaxant effect appears to be predominantly endothelium-dependent and NO-mediated (Beretta et al., 2009). Moreover, inhibition of cyclooxygenase (COX) by indomethacin significantly diminished sumac's vasodilatory effect, clearly suggestive of a role for COX enzymes in the observed vasorelaxation (Beretta et al., 2009). Importantly, this extract also possesses a potent anti-inflammatory capacity, evident by its ability to reduce ischemia-induced TNF- $\alpha$ (Beretta et al., 2009).

\section{Sesamum indicum (Sesame)}

Sesame is known to decrease BP as well as the heart rate in rats (Tabassum and Ahmad, 2011). Petroleum ether soluble fraction of root extract of sesame plant induced vasorelaxation, dose-dependently up to a $180 \mathrm{mg} / \mathrm{ml}$, in rat isolated aorta (Suresh Kumar et al., 2008). Introducing an eNOS inhibitor, LNAME, or removal of the endothelium decreased the extract's vasodilatory capacity (Suresh Kumar et al., 2008), indicative of a mechanism that relies on both the endothelium and NO generation (Table 2). An ethanolic seed extract of $S$. indicum also exhibits antioxidant activity, as it scavenges ROS, inhibits LDL peroxidation (Visavadiya et al., 2009) and enhances the kinetic properties of antioxidant enzymes (Tabassum and Ahmad, 2011; Table 1). Furthermore, in a randomized clinical trial among type 2 diabetics, patients consuming a paste of ground unhulled sesame seeds ( $28 \mathrm{~g} /$ day) exhibited a favorable modulation of several CVD risk factors, particularly a reduction in serum levels of triglycerides, (Mirmiran et al., 2013).

\section{Solanum (Tomato)}

Solanum sisymbriifolium (wild tomato) and Solanum paludosum Moric (SpM) exhibit hypotensive effects. Root extract of wild tomatoes is reported to decrease $\mathrm{BP}$ level in normotensive and hypertensive rats (Ibarrola et al., 1996, 2000, 2011). SpM $(75 \mu \mathrm{g} / \mathrm{ml})$ exhibits vasodilatory activities in rat aortic rings by a NO-dependent pathway (Monteiro et al., 2012; Table 2). In a double-blind, placebo-controlled pilot study, an antioxidant-rich tomato extract was shown to reduce both systolic and diastolic BP in grade-1 hypertension subjects (Engelhard et al., 2006). Importantly, tomato extract significantly lowered BP in patients with hypertension controlled with low doses of calcium-channel blockers or ACE inhibitors (Paran et al., 2009). In a randomized control trial, tomato extract was not found to have a BP-lowering effect in a pre-hypertensive population (Ried et al., 2009).

\section{Stephania tetrandra (Stephania Root; Fang Ji, etc.)}

Stephania tetrandra was able to normalize elevated BP in rats (Wong et al., 2000; Yu et al., 2004), as well as decrease heart rate (Wong et al., 2000) and inhibit hypertrophy (Yu et al., 2004). It can also relax rabbit penis (corpus cavernosum), possibly by reducing $\mathrm{Ca}^{2+}$-induced muscle contraction (Qian et al., 1983; Chen et al., 2009; Table 2). The main bioactive component of this plant is tetrandrine. Tetrandrine is reported to have antiinflammatory (Ferrante et al., 1990; Chen et al., 1997; Xie et al., 2002; Wu and Ng, 2007; Dang et al., 2014; Table 3) and antioxidant (Shi et al., 1995; Table 1) properties, both of which likely contribute to the antihypertensive effects of this plant.

\section{Tribulus terrestris (Bindii, Cat's Head, Devil's Eyelashes, etc.)}

Tribulus terrestris, or Bindii, is reported to reduce BP in SHR (Phillips et al., 2006) and two-kidney one-clip (2K-1C) rats (Sharifi et al., 2003). In the $2 \mathrm{~K}-1 \mathrm{C}$ rats, $10 \mathrm{mg} / \mathrm{kg}$ of Bindii also reduced ACE activity (Sharifi et al., 2003). The methanolic and aqueous extracts $(0.3-15 \mathrm{mg} / \mathrm{ml})$ exhibited vasodilatory effects in SHRs via a mechanism that appears to involve both $\mathrm{NO}$ 
release and membrane hyperpolarization (Phillips et al., 2006; Table 2). This plant is also reported to be used for its diuretic value in Indian folk medicine (Kumar et al., 2015). Moreover, total saponins of this plant inhibit Ang II-induced production of $\mathrm{H}_{2} \mathrm{O}_{2}$ (Table 1) as well as proliferation of VSMCs induced by Ang II (Li et al., 2013; Table 4).

\section{Tropaeolum majus L. (Garden Nasturtium, Monks Cress, etc.)}

Hydroethanolic extracts of Tropaeloum majus have shown a concentration-dependent reduction in MAP of SHR and normotensive rats (Gasparotto Junior et al., 2011) (Table 2). This hypotensive effect could be a result of different mechanisms. For instance, T. majus' ethanolic extract $(300 \mathrm{mg} / \mathrm{kg})$, purified fraction $(100 \mathrm{mg} / \mathrm{kg})$, or isoquercitrin $(10 \mathrm{mg} / \mathrm{kg})$, the plant's main component, are all known to exhibit diuretic activities in SHR (Gasparotto Junior et al., 2012; Table 5). This is thought to be a result of their ability to increase plasma aldosterone levels and downregulate sodium/potassium pump activities in the kidney (Gasparotto Junior et al., 2012). All the aforementioned components were able to reduce plasma ACE levels (Gasparotto Junior et al., 2011, 2012). Isoquercitrin, in particular, has also been reported to decrease ROS levels and increase NO production (Gasparotto Junior et al., 2012; Table 1).

\section{Viola odorata (Sweet Violet)}

Sweet violet leaves extract $(0.1,0.3$, and $1 \mathrm{mg} / \mathrm{kg})$ is reported to lower MAP of rats (Siddiqi et al., 2012; Table 2). The extract induced relaxation and also caused a rightward shift of $\mathrm{Ca}^{2+}$ concentration-response in a concentration-dependent $(0.3-3 \mathrm{mg} / \mathrm{ml})$ fashion (Siddiqi et al., 2012). This vasodilatory effect is thought to be mediated through NO production and $\mathrm{Ca}^{2+}$ influx control (Siddiqi et al., 2012). Relevantly, the extract favorably ameliorated CVD risk factors by causing a significant decrease in total cholesterol, LDL-C, and atherogenic index (Siddiqi et al., 2012). It also increased HDL-C levels, and prevented a body weight increase in Sprague-Dawley rats (Siddiqi et al., 2012).

\section{Viscum Articulatum Burm}

A traditional Chinese herb, Viscum articulatum Brum, has been used for treatment of hypertension. It has been reported to have diuretic activities, as its methanolic extract increased urine volume of normal (Jadhav et al., 2010) and L-NAME-treated rats (Bachhav et al., 2012; Table 5). In addition, oleanoic acid isolated from $V$. articulatum Brum $(60 \mathrm{mg} / \mathrm{kg} /$ day) can increase plasma NO levels, while also decreasing both lipid peroxidation in the heart and glucocorticoid-induced SBP (Bachhav et al., 2011; Tables 1, 2). An antioxidant potential of this plant has also been reported (Kuo et al., 2010; Table 1).

\section{OTHER LESS-STUDIED PLANTS WITH HYPOTENSIVE ACTIVITIES}

There are a considerable number of other plants that have been reported to induce hypotensive responses in different animal models of hypertension. Here we briefly discuss the ones that are not used as frequently as the above-mentioned plants and are not that well-studied.

Cnidium monnieri's osthol has been reported to decrease BP of both renovascular hypertensive rats $(20 \mathrm{mg} / \mathrm{kg}$; Zhou et al., 2012) and stroke-prone SHRs (0.05\% by weight; Ogawa et al., 2007), possibly through increasing antioxidant levels (Zhou et al., 2012; Table 1). Administration of an aqueous extract of Cuminum cyminum seeds $(200 \mathrm{mg} / \mathrm{kg}$ body weight for 9 weeks) to $2 \mathrm{~K}-1 \mathrm{C}$ rats also exhibits a BP-lowering effect. This fall in SBP was reported to arise from improvement in endothelial function reflected by upregulation of eNOS and hence augmented NO production, increase in expression of antioxidant system (thioredoxin 1 and thioredoxin reductase 1), and downregulation of inflammatory markers such as TNF- $\alpha$ and IL-6 (Kalaivani et al., 2013; Tables 1, 3).

Kalanchoe pinnata aqueous extract $(25-100 \mathrm{mg} / \mathrm{kg} /$ day) has been reported to also decrease $\mathrm{BP}$ and exhibit antioxidant activities in high salt-loaded rats (Bopda et al., 2014; Table 1). Peristrophe roxburghiana (Cheng et al., 2004) and Ranunculus japoniucus (Liu et al., 2012; Table 2) was able to lower BP of $2 \mathrm{~K}-1 \mathrm{C}$ rats, possibly through regulating $\mathrm{NO}$ and Ang II levels, respectively. Picrasma quassiodes has shown a hypotensive effect on SBP of SHR, which could be possibly related to modulating NO and SOD production (Zhao et al., 2013; Table 1). Scrophularia ningpoensis has shown an ameliorative effect on BP and heart rate of hypertensive rats, an effect that is possibly due to its ability to reduce levels of SOD and ET-1 (Gu and Chen, 2008).

Lithocarpus polystachyus Rehd (Hou et al., 2012) and Thymus serpyllum (Mihailovic-Stanojevic et al., 2013) were shown to decrease BP in SHR, while Thymelaea hirsuta has decreased BP of diabetic-hypertensive rats (Bnouham et al., 2012). Pueraria tuberosa is reported to reduce $\mathrm{BP}$ of stage 1 hypertensive humans (Verma et al., 2012). A mechanism for the hypotensive effect of these four herbs has not yet been elucidated.

Other plants may have potential hypotensive effect due to their effects on VSMCs. A mixture of Angelica sinensis and Ligusticum chuanxiong extract $(300 \mu \mathrm{g} / \mathrm{ml})$ has been reported to inhibit VSMCs proliferation by inducing a G0/G1 arrest (Hou et al., 2005; Table 4). Artemisia verlotorum Lamotte has shown a vasodilatory effect on isolated rat aorta, probably mediated via muscarinic receptor agonism and transduced through the NO/cGMP route (Calderone et al., 1999; Table 2). Bacopa monnieri also showed an NO-mediated vasodilatory effect on several types of blood vessels isolated from rats as well as decreasing BP (Kamkaew et al., 2011; Table 2). Its vasodilatory effect could also be a result of regulating $\mathrm{Ca}^{2+}$ levels (Kamkaew et al., 2011). A similar mechanism was also suggested for the vasorelaxant effect of an extract of Crotalaria sessiliflora $(0.5-5 \mathrm{mg} / \mathrm{ml})$ on rat thoracic aortic rings, where removal of endothelium, extracellular $\mathrm{Ca}^{2+}$ or inhibition with L-NAME abolished the relaxation of this conduit artery (Koh et al., 2007; Table 2). Euphorbia humifusa also elicited a vasodilatory effect on phenylephrine-induced contractions in rat aortic rings by modulating $\mathrm{NO}$ and $\mathrm{Ca}^{2+}$ levels (Wang et al., 2013; Table 2). Geum japonicum's extracts (acetone and butyl alcohol$30 \mu \mathrm{g} / \mathrm{ml}$ ) have been reported to lower BP in normotensive and hypertensive rats, and relax phenylephrine-induced contractions 
of rat aortic rings, while not affecting baseline tonicity, suggesting a normalizing role (Xie et al., 2007; Table 2). The mechanism for this plant appears to be dependent on both $\mathrm{NO}$ and cGMP production (Xie et al., 2007). Extracts from the roots of Microdesmis keayana $(0.5-50 \mathrm{mg} / \mathrm{ml})$ have shown ability to vasorelax aortic strips from normotensive rats and guinea pigs possibly by increased expression of eNOS (Zamblé et al., 2006; Table 2). Diterpenes isolated from Moldenhawera nutans (1$10 \mathrm{mg} / \mathrm{kg}$ ) have been able to reduce contractions induced by high potassium in isolated rat aorta, apparently through regulation of sympathetic tone (Lahlou et al., 2007; Table 2).

Several herbs have also been reported to inhibit contractions in blood vessels through an endothelium-dependent mechanism via enhancing NO production (Table 2). These include: Nitraria sibirica Pall (0.1-10 g/l, Senejoux et al., 2012); Oenothera odorata $(5.16 \mu \mathrm{g} / \mathrm{ml}$, Kim et al., 2011); Prunella vulgaris (100 and $200 \mathrm{mg} / \mathrm{kg}$, Hwang et al., 2012); Pseuderanthemum palatiferum (81 $\mu \mathrm{g} / \mathrm{ml}$, Khonsung et al., 2011); Peucedanum praeruptorum Dunn (1-100 $\mu \mathrm{M}$, Xu et al., 2010); Piper truncatum $(10.7 \mu \mathrm{g} / \mathrm{ml}$, Raimundo et al., 2009); Uncariae ramulus et Uncus (Goto et al., 1999); and Zizyphi Spinosi (Fu et al., 2011). Furthermore, Piper truncatum also seems to mediate its effect via histamine receptors (Raimundo et al., 2009). In addition to vasodilation, Peucedanum praeruptorum Dunn has also been reported to decrease smooth muscle size and collagen content (Xu et al., 2010). On the other hand, a couple of herbs' vasorelaxant effect is mediated by $\mathrm{Ca}^{2+}$ regulation. Petasites formosanus (10-100 $\mu \mathrm{M}$, Wang et al., 2002); and Piper nigrum (1-30 $\mu \mathrm{M}$, Taqvi et al., 2008); are reported to antagonize $\mathrm{Ca}^{2+}$ channels and produce vasodilation in blood vessels. Finally, Tridax procumbens $(0.15-1.05 \mathrm{mg} / \mathrm{ml})$ has been reported to relax norepinephrine, $\mathrm{KCl}$ and serotonininduced contractions in rat isolated aortic rings (Salahdeen and Murtala, 2012; Table 2); its mechanism has not yet been deciphered. Further in vivo investigations should be conducted to study and confirm the effect of these herbs and spices on hypertension.

Many other herbs and spices are reported to exhibit antioxidant activities. Radix Angelicae has been reported to increase cellular antioxidants, decrease proxidants and Ang II levels in 2K-1C rats (Cao et al., 2013; Tables 1, 2). Ferula gummosa (90 mg/kg; Gholitabar and Roshan, 2013) and Sambucus ebulus L. (200 ml/day) (Ivanova et al., 2014) were able to increase antioxidant enzymes in SHRs and healthy humans, respectively (Table 1). On the other hand, Desmodium gangeticum (Sankar et al., 2013) has been shown to reduce ROS levels in cardiomyocytes (Table 1). Cnidium officinale (Jeong et al., 2009) and Suaeda asparagoides (Park et al., 2007) possess antioxidant properties as confirmed by the DPPH enzymatic assay (Table 1). These antioxidant activities indicate a potential role in hypertension treatment that should be explored further for vasorelaxant activity.

Finally, several herbs and spices have been reported to demonstrate hypotensive properties. For example, Radix astragali regulates expression of eNOS and ET-1, as well as inhibit vascular remodeling in pulmonary arteries (He et al., 1999). Sophora flavescens Ait $(0.5-2 \mathrm{mg} / \mathrm{ml})$ has been reported to reduce expression of IL-6, VCAM-1, and ET-1 in addition to inhibiting proliferation of VSMCs in monocrotaline-induced pulmonary hypertension in rats (Zhang et al., 2014; Tables 3, 4). Sorbus cortex (100 and $200 \mathrm{mg} / \mathrm{kg}$ ) is reported to regulate NO and ET1 , as well as decrease inflammatory markers (NF- $\kappa$ B, VCAM-1, ICAM-1) and media/lumen ratio in rats fed an atherogenic diet (Sohn et al., 2005; Tables 2-4). Rheum rhabarbarum's aqueous extracts decreased ET-1, VCAM-1, and LDL levels (Moon et al., 2008). Scutellariae radix increased NO levels (Chen et al., 2013; Table 3).

\section{EPIGENETIC ALTERATIONS IN HYPERTENSION, AND CORRECTION BY CONSUMPTION OF HERBS AND THEIR CONSTITUENTS}

Three decades have elapsed since an association between epigenetic modification (DNA methylation) and disease was first recognized (Feinberg and Vogelstein, 1983). Subsequently, this has been further expanded through research into chromatin and histone modifications, and RNA-driven mechanisms (micro RNAs). These molecular factors are involved in the modification of the genetic material, without any alteration in the nucleotide sequence. Interestingly, cardiovascular pathological processes such as oxidative stress, proliferation, and inflammation can be ameliorated by preventing hypermethylation and regulation of epigenetic balance between histone acetyl transferases (HAT) and histone deacetylases (HDAC)/lysine deacetylases (KDACs; Millis, 2011; Sunagawa et al., 2011; Baccarelli and Ghosh, 2012; Stefanska et al., 2012).

\section{Epigenetic Alterations}

Accumulating data provides clear evidence that epigenetic processes play a significant role in many CVDs, including atherosclerosis (Turunen et al., 2009) and hypertension (Millis, 2011; Cowley et al., 2012; Yang et al., 2015). One of the most common epigenetic modifications is DNA methylation. Importantly, this modification plays vital roles in the regulation of transcriptional machinery and is thus implicated in several diseases, including CVDs (Bjornsson et al., 2004; Feinberg, 2008). Unlike DNA base sequences, these epigenetic modifications are potentially reversible, making them attractive targets in modern or personalized medicine.

The degree of eNOS expression is a robust biomarker for vascular tone and BP regulation. One of the mechanisms by which eNOS expression is regulated takes place via epigenetic mechanisms. For instance, oxidized LDL increases Histone 3 Lysine 9 (H3K9) methylation of eNOS promoter in endothelial cells (Fang et al., 2011). It also concurrently decreases acetylation of $\mathrm{H} 3$ and $\mathrm{H} 4$ as well as methylation of Histone 3 Lysine 4 (H3K4) in the proximity of eNOS promoter (Fang et al., 2011). Together, these findings are indicative of down-regulation of eNOS expression and thus a decrease in the bioavailability of NO (Fang et al., 2011). Moreover, in H3K4/K9 demethylase (LSD1)-deficient mice, eNOS expression is diminished, further implicating the role of histone methylation in vascular tone (Fish et al., 2010). 
As is well known, the kidney plays an integral role in regulating systemic blood pressure. Notably, kidney functions appear to be significantly affected by the individual's global methylation profile (Beckerman et al., 2014; Wing et al., 2014).

The role of histone modifications in vascular tone is also evident in the regulation of endothelin ( $\mathrm{Yu}$ et al., 2015), the most potent natural vasoconstrictor. There is increasing evidence to support the notion that endothelin promoter transactivation may be regulated by epigenetic mechanisms. Indeed, an increase in the histone acetyltransferase p300 has been shown to be accompanied with increased release of endothelin (Chiu et al., 2009). Another relevant observation is that treatment of endothelial cells with pro-inflammatory stimuli leads to increased $\mathrm{H} 4$ acetylation in the endothelin promoter (Wort et al., 2009). Moreover, epigenetic modulation appears to be an important contributor to endothelin-induced expression of proinflammatory genes in VSMCs (Yang et al., 2014). Interestingly, epigenetic regulation of endothelin can also be seen in other CVDs like cardiac hypertrophy (Czubryt, 2015).

\section{Nutrients Deficient in Methyl Donors}

Diets deficient in methyl donors, like betaine, choline, folate, and methionine are a pointer to dysregulation of metabolic and cardiovascular function (Stefanska et al., 2012). This is mainly caused by disturbances in DNA hypomethylation, plasma homocysteinemia, increases in S-adenosylhomocysteine (SAH), reduction in S-adenosylmethionine (methyl donor), and an unfavorable plasma lipid composition (Stefanska et al., 2012). This milieu can be considered as a contributory risk factor for the pathogenesis of cardiovascular diseases (Zawada et al., 2014). Notably, ingestion of phytochemicals could be very beneficial in adjusting the level of hypomethylation (Stefanska et al., 2012). Folate acts as a methyl donor and is important for synthesis and regulation of DNA. Indeed, a diet containing low folate content prior to pregnancy has a bearing on the future offspring and its health into adult-life, causing an obese phenotype and increasing the risk of hypertension (Sinclair et al., 2007). In contrast, a methyl-rich diet during pregnancy protects the offspring from developing the obese phenotype (Dolinoy et al., 2006).

\section{Involvement of Herb- and Plant-Derivatives in the Modulation of Epigenetic Machinery}

Epigenetic changes can be reversed chemically, and are receiving considerable attention by the scientific community and pharmaceutical industry. Pertinently, herbs and herb-derived molecules are at the forefront of research for their potential application in modulating the histone structure (Figure 1).

Recently, a comprehensive survey of Traditional Chinese Medicinals (TCMs), of which $95 \%$ are plants, was conducted. The goal of this study was to determine the potential epigenetic effects of these medicinals. Nearly $36 \%$ of these TCMs appeared to interact with human enzymes possessing histone-modifying capacities (Hsieh et al., 2013). Amongst this subset of therapeutic agents, 56\% appeared to promote histone condensation (Hsieh et al., 2013), a mechanism that has significant implications in the pathophysiology of many diseases, including CVDs.

Methylation can be inhibited by Hesperidin (citrus) and Lycopene (tomatoes). Furthermore, catechins (present in tea), curcumin (in turmeric), and coumaric acid (in cinnamon) are known inhibitors of acetylation and methylation; and constituents of garlic (allyl sulfides) can also inhibit histone deacetylases (Kirk et al., 2008; Morimoto et al., 2008; Reuter et al., 2011; Shankar et al., 2013). A polyherbal mixture was recently shown to regulate class I and II histone deacetylases (Huang et al., 2014). Tanshinone 1, isolated from Salvia miltiorrhiza has been shown to repress acetylation of histone H3 (Gong et al.,

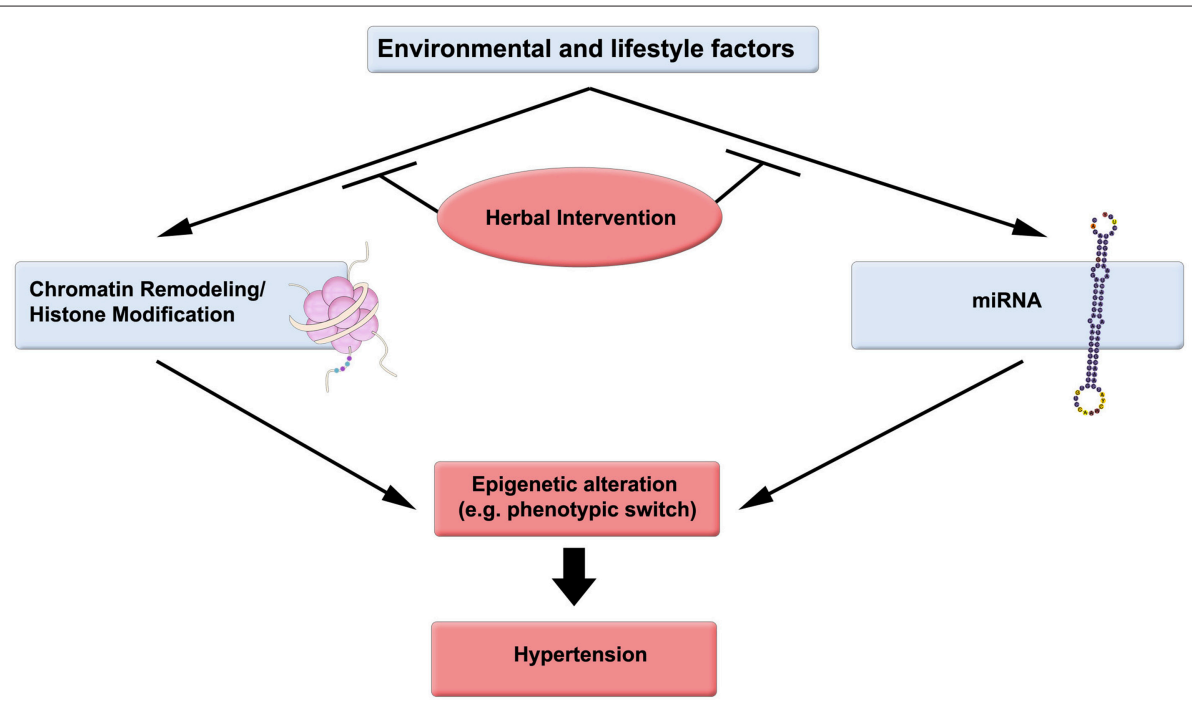

FIGURE 1 | Epigenetic-driven hypertension could be ameliorated by consumption of herbs and other factors. Environmental and lifestyle factors such as diet (high fat and carbohydrate, low protein; minimal fruit, herb, and vegetable consumption), and Physical Activity (Lack of exercise-sedentary lifestyle) significantly affect DNA methylation, chromatin remodeling, and miRNA regulation. Herbal intervention can favorably modulate these epigenetic modifiers. 
2012). In addition, PPAR $\gamma$, which is well-known for its role in cardiovascular physiology including the regulation of $\mathrm{BP}$, is epigenetically regulated by rosmarinic acid (Yang et al., 2012).

As a note of caution, one drawback of these plant-derived bioactive components is their poor bioavailability; however, with structural modifications of the different parent molecules and/or improvement in delivery to identified locations will prove to be therapeutically beneficial. Clearly, further in vivo investigations are required to realize the full potential of these epigenomic modifiers.

\section{Micro RNAs (miRNAs)}

Inclusion of non-coding RNAs (including miRNAs) in epigenomic machinery is a controversial subject (Choudhuri, 2011). However, both in health and disease states, noncoding RNAs play a major part in the regulation of epigenome, particularly targeting the associated enzymes at the posttranscriptional level (Iorio et al., 2010). MiRNAs, short-chain $(\sim 22)$ ribonucleotides, have received most of the attention compared to other members of the non-coding RNA group. Several hundreds have been identified, and increasing evidence implicates miRNAs in the development of hypertension (Marques et al., 2015). In this context, alternate expression of these molecular entities has been reported in hypertensive subjects, the expression of miR-27a, miR-150, and miR-192 was suppressed, whereas miR-92a, miR-130a, and miR-195 were upregulated in hypertensive patients (Marques et al., 2015). Moreover, blood concentrations of microRNAs (miR17, miR126, miR145, miR222) are associated with cardiovascular derangements, such as downregulation of eNOS that would lead to an increase in arterial tone and hence elevated BP (Baccarelli and Ghosh, 2012).

Interestingly, recent evidence shows that herbs and their components may play an important role in miRNA-related health benefits and pathologies (Stefanska et al., 2012; Wu et al., 2015). For example, grape extract has recently been shown to possess a beneficial immunomodulatory effect in hypertensives by virtue of its ability to downregulate miRNAs implicated in inflammation (Tomé-Carneiro et al., 2013).

\section{LIMITATIONS}

Despite the multi-beneficial effects of consuming herbs in managing and treating several diseases, including hypertension, herbal medicine is not without many limitations. These include:

a. Lack of sufficient quality control due to the absence of governmental or other health-related bodies overseeing the production and other relevant issues pertaining to herbal medicine, practice, and products.

b. Undesired side effects which may not always be very obvious or immediate.

c. Allergy to some components of the herb (or the herbal product).

d. Seasonal variations in the content of the herbal plant parts (both aerial: bark, leaves, flowers, fruits seeds or stems, and underground: rhizomes or roots) and thus the potential quantitative changes in composition and/or ratios of bioactive ingredients.

e. Drug interactions with other medicines.

f. Adulteration of medications, where herbal prescriptions could be mixed with synthetic drugs like pain-killers or anti-inflammatory corticosteroids.

g. Long time needed for an effect to be observed in some cases, which consequently precludes the use of the herb/herbal compound when an immediate resolution to the medical problem is needed.

h. Limitations in certain diseases, since herbal medicine cannot be used to heal a concussion, broken bone or a heart attack.

i. Misclassification of the herb/plant which may sometimes lead to misidentification.

j. Lack of enough information on labels of bottles of herbal products, such as expiry dates (and how this affects the function; related to point "a" above).

k. Lack of awareness among patients, physicians and the average public about the use or abuse of herbs and herbrelated products.

1. Self-medication due to over-the-counter availability of many herbal products.

m. Large number of similar herbs in respective pharmacopeias.

\section{CONCLUSION}

In this review, we highlighted the antihypertensive therapeutic benefits of plants and herbs. Premise of our argument is for a consistent, favorable outcome with herbal treatment for hypertension. The salient features cohesive to this thesis have illuminated the following: the augmentation of NO secretion via increase in expression and/or activity of eNOS; abatement of ROS levels through suppression of oxidant enzymes and an equilibrium shift toward increased expression of anti-oxidative enzymes and related molecules; inhibition of ACE and dyslipidemia. Together, all these favorable herb-modulated parameters are directed toward normalization in vascular function, alterations in actions of transcription factors $(\mathrm{NF}-\kappa \mathrm{B})$, down-regulation of pro-inflammatory pathways, and improvement in renal physiopharmacology (diuretic process). The overarching property of the aforementioned herbs is the reduction/normalization of BP.

A large percentage of hypertensive patients are certainly treatable by appropriate adaptation of life-style changes, such as shift from a sedentary (couch potato) setting to a more active, exercise-orientated healthy lifestyle. In addition to above, ingestion/consumption of functionally bioactive nutrients, such as the aforementioned phenolic-rich and other botanical-derived pharmacological agents, would be beneficial ("tonics" for most diseases) to normal health. Therefore, such judicious modifications will not only ameliorate hypertension, but simultaneously diminish the onset of atherothrombogenic diseases (coronary arterial disease, peripheral arterial, and cerebrovascular diseases; Saleh Al-Shehabi et al., 2015). Moreover, the burden on scarce national health budgets will decrease. 
Finally, there is an urgent need for more rigorous, welldeveloped clinical trials to obtain concrete evidence of beneficial impact of herbs and plants on hypertension and disease-free living. However, this must not detract from the evidence garnered herein from different animal models and human studies on the therapeutic benefits of herbs and plants.

\section{AUTHOR CONTRIBUTIONS}

All authors contributed to the writing of this mansucipt. AE conceived, designed, and revised the manuscript.

\section{REFERENCES}

Aaronson, P. I., McKinnon, W., and Poston, L. (1996). Mechanism of butyrateinduced vasorelaxation of rat mesenteric resistance artery. Br. J. Pharmacol. 117, 365-371. doi: 10.1111/j.1476-5381.1996.tb15200.x

Ajagbonna, O. P., Mojiminiyi, F., and Sofola, O. (2001). Relaxant effects of the aqueous leaf extract of cassia occidentailis on rat aortic rings. Afr. J. Biomed. Res. 4, 127-129. doi: 10.4314/ajbr.v4i3.53893

Akilen, R., Pimlott, Z., Tsiami, A., and Robinson, N. (2013). Effect of short-term administration of cinnamon on blood pressure in patients with prediabetes and type 2 diabetes. Nutrition 29, 1192-1196. doi: 10.1016/j.nut.2013.03.007

Al Disi, S.S, Anwar, M. A., and Eid, A. H. (2015). Anti-Hypertensive Herbs and their Mechanisms of Action: Part I. Front. Pharmacol. 6:323. doi: 10.3389/fphar.2015.00323

Amaechina, F. C., and Omogbai, E. K. (2007). Hypotensive effect of aqueous extract of the leaves of Phyllanthus amarus Schum and Thonn (Euphorbiaceae). Acta Pol. Pharm. 64, 547-552.

Amrani, S., Harnafi, H., Gadi, D., Mekhfi, H., Legssyer, A., Aziz, M., et al. (2009). Vasorelaxant and anti-platelet aggregation effects of aqueous Ocimum basilicum extract. J. Ethnopharmacol. 125, 157-162. doi: 10.1016/j.jep.2009.05.043

An, S. M., Park, C. H., Heo, J. C., Park, J. Y., Woo, S. U., Seo, J. H., et al. (2007). Gastrodia elata Blume protects against stress-induced gastric mucosal lesions in mice. Int. J. Mol. Med. 20, 209-215. doi: 10.3892/ijmm.20.2.209

Andersson, K. E., and Hellstrand, P. (2012). Dietary oats and modulation of atherogenic pathways. Mol. Nutr. Food Res. 56, 1003-1013. doi: $10.1002 / \mathrm{mnfr} .201100706$

Astulla, A., Zaima, K., Matsuno, Y., Hirasawa, Y., Ekasari, W., Widyawaruyanti, A., et al. (2008). Alkaloids from the seeds of Peganum harmala showing antiplasmodial and vasorelaxant activities. J. Nat. Med. 62, 470-472. doi: 10.1007/s11418-008-0259-7

Azimi, P., Ghiasvand, R., Feizi, A., Hosseinzadeh, J., Bahreynian, M., Hariri, M., et al. (2016). Effect of cinnamon, cardamom, saffron and ginger consumption on blood pressure and a marker of endothelial function in patients with type 2 diabetes mellitus: a randomized controlled clinical trial. Blood Press. doi: 10.3109/08037051.2015.1111020. [Epub ahead of print].

Baccarelli, A., and Ghosh, S. (2012). Environmental exposures, epigenetics and cardiovascular disease. Curr. Opin. Clin. Nutr. Metab. Care 15, 323-329. doi: 10.1097/MCO.0b013e328354bf5c

Bachhav, S. S., Bhutada, M. S., Patil, S. D., Baser, B., and Chaudhari, K. B. (2012). Effect of viscum articulatum burm. (Loranthaceae) in Nomeganitro-L-arginine methyl ester induced hypertension and renal dysfunction. J. Ethnopharmacol. 142, 467-473. doi: 10.1016/j.jep.2012.05.021

Bachhav, S. S., Patil, S. D., Bhutada, M. S., and Surana, S. J. (2011). Oleanolic acid prevents glucocorticoid-induced hypertension in rats. Phytother. Res. 25, 1435-1439. doi: 10.1002/ptr.3431

Bahem, R., Hoffmann, A., Azonpi, A., Caballero-George, C., and Vanderheyden, P. (2015). Modulation of calcium signaling of angiotensin AT1, endothelin ETA, and ETB receptors by silibinin, quercetin, crocin, diallyl sulfides, and ginsenoside Rb1. Planta Med. 81, 670-678. doi: 10.1055/s-0034-1383408

Bai, Y., Lu, P., Han, C., Yu, C., Chen, M., He, F., et al. (2012). Hydroxysafflor yellow A (HSYA) from flowers of Carthamus tinctorius L. and its

\section{ACKNOWLEDGMENTS}

The authors would like to thank Miss Tuqa Saleh Al Shehabi for her assitance in drawing the figures. The authors would like to apologize to many of our research colleagues whose work could not be cited (in both parts of this review, I and II) due to limitations in mansucript length. Funding: This publication was made possible by grant \# NPRP 4-571-3-171 from the Qatar National Research Fund (a member of Qatar Foundation). The Statements made herein are solely the responsibility of the authors. This grant was awarded to AE.

vasodilatation effects on pulmonary artery. Molecules 17, 14918-14927. doi: $10.3390 /$ molecules 171214918

Baumann, G., Felix, S., Sattelberger, U., and Klein, G. (1990). Cardiovascular effects of forskolin (HL 362) in patients with idiopathic congestive cardiomyopathy-a comparative study with dobutamine and sodium nitroprusside. J. Cardiovasc. Pharmacol. 16, 93-100. doi: 10.1097/00005344-199007000-00013

Beckerman, P., Ko, Y.-A., and Susztak, K. (2014). Epigenetics: a new way to look at kidney diseases. Nephrol. Dial. Trans. 29, 1821-1827. doi: 10.1093/ndt/gfu026

Beevi, S. S., Narasu, M. L., and Gowda, B. B. (2010). Polyphenolics profile, antioxidant and radical scavenging activity of leaves and stem of Raphanus sativus L. Plant Foods Hum. Nutr. 65, 8-17. doi: 10.1007/s11130-0090148-6

Beretta, G., Rossoni, G., Santagati, N. A., and Facino, R. M. (2009). Anti-ischemic activity and endothelium-dependent vasorelaxant effect of hydrolysable tannins from the leaves of Rhus coriaria (Sumac) in isolated rabbit heart and thoracic aorta. Planta Med. 75, 1482-1488. doi: 10.1055/s-0029-1185797

Berrougui, H., Herrera-Gonzalez, M. D., Marhuenda, E., Ettaib, A., and Hmamouchi, M. (2002). Relaxant activity of methanolic extract from seeds of Peganum harmala on isolated rat aorta. Therapie 57, 236-241.

Berrougui, H., Martin-Cordero, C., Khalil, A., Hmamouchi, M., Ettaib, A., Marhuenda, E., et al. (2006). Vasorelaxant effects of harmine and harmaline extracted from Peganum harmala L. seeds in isolated rat aorta. Pharmacol. Res. 54, 150-157. doi: 10.1016/j.phrs.2006.04.001

Bhandari, U., Ansari, M. N., and Islam, F. (2008a). Cardioprotective effect of aqueous extract of Embelia ribes Burm fruits against isoproterenol-induced myocardial infarction in albino rats. Indian J. Exp. Biol. 46, 35-40. doi: 10.1016/S1567-5688(08)70683-4

Bhandari, U., Jain, N., Ansari, M. N., and Pillai, K. K. (2008b). Beneficial effect of Embelia ribes ethanolic extract on blood pressure and glycosylated hemoglobin in streptozotocin-induced diabetes in rats. Fitoterapia 79, 351-355. doi: 10.1016/j.fitote.2008.04.001

Bjornsson, H. T., Fallin, M. D., and Feinberg, A. P. (2004). An integrated epigenetic and genetic approach to common human disease. Trends Genetics 20, 350-358. doi: 10.1016/j.tig.2004.06.009

Bnouham, M., Benalla, W., Bellahcen, S., Hakkou, Z., Ziyyat, A., Mekhfi, H., et al. (2012). Antidiabetic and antihypertensive effect of a polyphenol-rich fraction of Thymelaea hirsuta L. in a model of neonatal streptozotocin-diabetic and N(G) -nitro-l-arginine methyl ester-hypertensive rats. J. Diabetes 4, 307-313. doi: 10.1111/j.1753-0407.2012.00202.x

Bopda, O. S., Longo, F., Bella, T. N., Edzah, P. M., Taiwe, G. S., Bilanda, D. C., et al. (2014). Antihypertensive activities of the aqueous extract of Kalanchoe pinnata (Crassulaceae) in high salt-loaded rats. J. Ethnopharmacol. 153, 400-407. doi: 10.1016/j.jep.2014.02.041

Brankovic, S., Radenkovic, M., Kitic, D., Veljkovic, S., Ivetic, V., Pavlovic, D., et al. (2011). Comparison of the hypotensive and bradycardic activity of ginkgo, garlic, and onion extracts. Clin. Exp. Hypertens. 33, 95-99. doi: $10.3109 / 10641963.2010 .531833$

Builders, M. I., Uguru, M. O., and Aguiyi, C. (2012). Antiplasmodial potential of the African mistletoe: Agelanthus dodoneifolius polh and wiens. Indian J. Pharm. Sci. 74, 223-229. doi: 10.4103/0250-474X.106064

Calderone, V., Martinotti, E., Baragatti, B., Breschi, M. C., and Morelli, I. (1999). Vascular effects of aqueous crude extracts of Artemisia verlotorum Lamotte 
(Compositae): in vivo and in vitro pharmacological studies in rats. Phytother. Res. 13, 645-648.

Candan, F., and Sökmen, A. (2004). Effects of Rhus coriaria L (Anacardiaceae) on lipid peroxidation and free radical scavenging activity. Phytother. Res. 18, 84-86. doi: $10.1002 /$ ptr. 1228

Cao, Y. J., He, X., Wang, N., and He, L. C. (2013). Effects of imperatorin, the active component from Radix Angelicae (Baizhi), on the blood pressure and oxidative stress in $2 \mathrm{~K}, 1 \mathrm{C}$ hypertensive rats. Phytomedicine 20, 1048-1054. doi: 10.1016/j.phymed.2013.04.021

Carré, G., Carreyre, H., Ouedraogo, M., Becq, F., Bois, P., Thibaudeau, S., et al. (2014). The hypotensive agent dodoneine inhibits L-type Ca2+ current with negative inotropic effect on rat heart. Eur. J. Pharmacol. 728, 119-127. doi: 10.1016/j.ejphar.2014.01.059

Carre, G., Ouedraogo, M., Magaud, C., Carreyre, H., Becq, F., Bois, P., et al. (2015). Vasorelaxation induced by dodoneine is mediated by calcium channels blockade and carbonic anhydrase inhibition on vascular smooth muscle cells. J. Ethnopharmacol. 169, 8-17. doi: 10.1016/j.jep.2015.03.037

Chaudhari, H. S., Bhandari, U., and Khanna, G. (2012). Preventive effect of embelin from Embelia ribes on lipid metabolism and oxidative stress in high-fat diet-induced obesity in rats. Planta Med. 78, 651-657. doi: 10.1055/s-00311298379

Chen, C., Wang, Z., Wang, L., Yang, L., Ding, M., Ding, C., et al. (2012). Puerarin induces mitochondria-dependent apoptosis in hypoxic human pulmonary arterial smooth muscle cells. PLoS ONE 7:e34181. doi: 10.1371/journal.pone.0034181

Chen, C., Wang, Z. Y., Wang, L. X., Du, X. H., and Zhao, X. W. (2011). [Effects of puerarin on proliferation, apoptosis and Kv1.5 gene expression of pulmonary artery smooth muscle cells induced by hypoxia]. Zhonghua Lao Dong Wei Sheng Zhi Ye Bing Za Zhi 29, 731-734.

Chen, F., Sun, S., Kuhn, D. C., Lu, Y., Gaydos, L. J., Shi, X., et al. (1997). Tetrandrine inhibits signal-induced NF-kappa B activation in rat alveolar macrophages. Biochem. Biophys. Res. Commun. 231, 99-102. doi: 10.1006/bbrc.1997.6057

Chen, J., Liu, J., Wang, T., Xiao, H., Yin, C., Yang, J., et al. (2009). The relaxation mechanisms of tetrandrine on the rabbit corpus cavernosum tissue in vitro. Nat. Prod. Res. 23, 112-121. doi: 10.1080/14786410801886831

Chen, Z., Nihei, K., Tanaka, H., Uda, Y., and Kabuyama, Y. (2013). Identification of a nitric oxide generation-stimulative principle in Scutellariae radix. Biosci. Biotechnol. Biochem. 77, 657-659. doi: 10.1271/bbb.120800

Cheng, Y., Zhou, M., and Wang, Y. (2016). Arctigenin antagonizes mineralocorticoid receptor to inhibit the transcription of $\mathrm{Na} / \mathrm{K}$ ATPase. J. Recept. Signal Transduct. Res. 36, 181-188. doi: 10.3109/10799893.2015.1075039

Cheng, Z., Lü, J., and Liu, J. (2004). [Effects of Peritrophe roxburghiana on blood pressure in renal hypertensive and hyperlipidemic rats]. Zhong Yao Cai 27, 927-930.

Chiu, J., Khan, Z. A., Farhangkhoee, H., and Chakrabarti, S. (2009). Curcumin prevents diabetes-associated abnormalities in the kidneys by inhibiting p300 and nuclear factor-kappaB. Nutrition 25, 964-972. doi: 10.1016/j.nut.2008.12.007

Choi, D. H., Lee, Y. J., Kim, E. J., Li, X., Kim, H. Y., Hwang, S. M., et al. (2010). Ethanol Extract of Cynanchum wilfordii produces endothelium-dependent relaxation in rat aorta and anti-inflammatory activity in human aortic smooth muscle cells. J. K. Orient. Med. 31, 47-57.

Choi, D. H., Lee, Y. J., Kim, J. S., Kang, D. G., and Lee, H. S. (2012a). Cynanchum wilfordii ameliorates hypertension and endothelial dysfunction in rats fed with high fat/cholesterol diets. Immunopharmacol. Immunotoxicol. 34, 4-11. doi: 10.3109/08923973.2011.569889

Choi, D. H., Lee, Y. J., Oh, H. C., Cui, Y. L., Kim, J. S., Kang, D. G., et al. (2012b). Improved endothelial dysfunction by Cynanchum wilfordii in apolipoprotein E(-/-) mice fed a high fat/cholesterol diet. J. Med. Food 15, 169-179. doi: 10.1089/jmf.2010.1222

Choudhuri, S. (2011). From Waddington's epigenetic landscape to small noncoding RNA: some important milestones in the history of epigenetics research. Toxicol. Mech. Methods 21, 252-274. doi: $10.3109 / 15376516.2011 .559695$

Chung, D. H., Kim, S. H., Myung, N., Cho, K. J., and Chang, M. J. (2012). The antihypertensive effect of ethyl acetate extract of radish leaves in spontaneously hypertensive rats. Nutr. Res. Pract. 6, 308-314. doi: 10.4162/nrp.2012.6.4.308
Cowley, A. W. Jr., Nadeau, J. H., Baccarelli, A., Berecek, K., Fornage, M., Gibbons, G. H., et al. (2012). Report of the National Heart, Lung, and Blood Institute Working Group on epigenetics and hypertension. Hypertension 59, 899-905. doi: 10.1161/HYPERTENSIONAHA.111.190116

Czubryt, M. P. (2015). Going the distance: epigenetic regulation of endothelial endothelin-1 controls cardiac hypertrophy. J. Mol. Cell. Cardiol. 82, 60-62. doi: 10.1016/j.yjmcc.2015.02.028

da Cunha, G. H., de Moraes, M. O., Fechine, F. V., Frota Bezerra, F. A., Silveira, E. R., Canuto, K. M., et al. (2013). Vasorelaxant and antihypertensive effects of methanolic fraction of the essential oil of Alpinia zerumbet. Vascul. Pharmacol. 58, 337-345. doi: 10.1016/j.vph.2013.04.001

Dang, Y., Xu, Y., Wu, W., Li, W., Sun, Y., Yang, J., et al. (2014). Tetrandrine suppresses lipopolysaccharide-induced microglial activation by inhibiting NFkappaB and ERK signaling pathways in BV2 cells. PLoS ONE 9:e102522. doi: 10.1371/journal.pone.0102522

Davy, B. M., Melby, C. L., Beske, S. D., Ho, R. C., Davrath, L. R., and Davy, K. P. (2002). Oat consumption does not affect resting casual and ambulatory 24$\mathrm{h}$ arterial blood pressure in men with high-normal blood pressure to stage I hypertension. J. Nutr. 132, 394-398.

de Moura, R. S., Emiliano, A. F., de Carvalho, L. C., Souza, M. A., Guedes, D. C., Tano, T., et al. (2005). Antihypertensive and endothelium-dependent vasodilator effects of Alpinia zerumbet, a medicinal plant. J. Cardiovasc. Pharmacol. 46, 288-294. doi: 10.1097/01.fjc.0000175239.26326.47

Di, K. P., and Chang, L. G. (2007). [Experimental study of inhibition of safflower injection on mesenteric microvascular motion in rabbits DI]. Zhongguo Zhong Xi Yi Jie He Za Zhi 27, 339-342.

Dolinoy, D. C., Weidman, J. R., Waterland, R. A., and Jirtle, R. L. (2006). Maternal genistein alters coat color and protects Avy mouse offspring from obesity by modifying the fetal epigenome. Environ. Health Perspect. 114, 567-572. doi: 10.1289/ehp. 8700

Dubey, M. P., Srimal, R. C., Nityanand, S., and Dhawan, B. N. (1981). Pharmacological studies on coleonol, a hypotensive diterpene from Coleus forskohlii. J. Ethnopharmacol. 3, 1-13. doi: 10.1016/0378-8741(81) 90010-6

El Bardai, S., Lyoussi, B., Wibo, M., and Morel, N. (2001). Pharmacological evidence of hypotensive activity of Marrubium vulgare and Foeniculum vulgare in spontaneously hypertensive rat. Clin. Exp. Hypertens. 23, 329-343. doi: 10.1081/CEH-100102671

El Bardai, S., Lyoussi, B., Wibo, M., and Morel, N. (2004). Comparative study of the antihypertensive activity of Marrubium vulgare and of the dihydropyridine calcium antagonist amlodipine in spontaneously hypertensive rat. Clin. Exp. Hypertens. 26, 465-474. doi: 10.1081/CEH-200031818

El Bardai, S., Morel, N., Wibo, M., Fabre, N., Llabres, G., Lyoussi, B., et al. (2003). The vasorelaxant activity of marrubenol and marrubiin from Marrubium vulgare. Planta Med. 69, 75-77. doi: 10.1055/s-2003-37042

El-Bardai, S., Wibo, M., Hamaide, M. C., Lyoussi, B., Quetin-Leclercq, J., and Morel, N. (2003). Characterisation of marrubenol, a diterpene extracted from Marrubium vulgare, as an L-type calcium channel blocker. $\mathrm{Br}$. J. Pharmacol. 140, 1211-1216. doi: 10.1038/sj.bjp.0705561

Engelhard, Y. N., Gazer, B., and Paran, E. (2006). Natural antioxidants from tomato extract reduce blood pressure in patients with grade-1 hypertension: a double-blind, placebo-controlled pilot study. Am. Heart J. 151, 100. doi: 10.1016/j.ahj.2005.05.008

Fan, Q. L., Zhu, Y. D., Huang, W. H., Qi, Y., and Guo, B. L. (2014). Two new acylated flavonol glycosides from the seeds of Lepidium sativum. Molecules 19, 11341-11349. doi: 10.3390/molecules190811341

Fang, F., Yang, Y., Yuan, Z., Gao, Y., Zhou, J., Chen, Q., et al. (2011). Myocardinrelated transcription factor A mediates OxLDL-induced endothelial injury. Circ. Res. 108, 797-807. doi: 10.1161/CIRCRESAHA.111.240655

Feinberg, A. P. (2008). Epigenetics at the epicenter of modern medicine. JAMA 299, 1345-1350. doi: 10.1001/jama.299.11.1345

Feinberg, A. P., and Vogelstein, B. (1983). Hypomethylation distinguishes genes of some human cancers from their normal counterparts. Nature 301, 89-92. doi: 10.1038/301089a0

Ferrante, A., Seow, W. K., Rowan-Kelly, B., and Thong, Y. H. (1990). Tetrandrine, a plant alkaloid, inhibits the production of tumour necrosis factor-alpha (cachectin) hy human monocytes. Clin. Exp. Immunol. 80, 232-235. doi: 10.1111/j.1365-2249.1990.tb05239.x 
Fish, J. E., Yan, M. S., Matouk, C. C., St Bernard, R., Ho, J. J., Gavryushova, A., et al. (2010). Hypoxic repression of endothelial nitric-oxide synthase transcription is coupled with eviction of promoter histones. J. Biol. Chem. 285, 810-826. doi: 10.1074/jbc.M109.067868

Flint, A. J., Hu, F. B., Glynn, R. J., Jensen, M. K., Franz, M., Sampson, L., et al. (2009). Whole grains and incident hypertension in men. Am. J. Clin. Nutr. 90, 493-498. doi: 10.3945/ajen.2009.27460

Fu, J. Y., Qian, L. B., Zhu, L. G., Liang, H. T., Tan, Y. N., Lu, H. T., et al. (2011). Betulinic acid ameliorates endothelium-dependent relaxation in L-NAMEinduced hypertensive rats by reducing oxidative stress. Eur. J. Pharm. Sci. 44, 385-391. doi: 10.1016/j.ejps.2011.08.025

Gasparotto Junior, A., Gasparotto, F. M., Lourenco, E. L., Crestani, S., Stefanello, M. E., Salvador, M. J., et al. (2011). Antihypertensive effects of isoquercitrin and extracts from Tropaeolum majus L.: evidence for the inhibition of angiotensin converting enzyme. J. Ethnopharmacol. 134, 363-372. doi: 10.1016/j.jep.2010.12.026

Gasparotto Junior, A., Prando, T. B., Leme Tdos, S., Gasparotto, F. M., Lourenco, E. L., Rattmann, Y. D., et al. (2012). Mechanisms underlying the diuretic effects of Tropaeolum majus L. extracts and its main component isoquercitrin. J. Ethnopharmacol. 141, 501-509. doi: 10.1016/j.jep.2012.03.018

Ghayur, M. N., and Gilani, A. H. (2006). Radish seed extract mediates its cardiovascular inhibitory effects via muscarinic receptor activation. Fundam. Clin. Pharmacol. 20, 57-63. doi: 10.1111/j.1472-8206.2005.00382.x

Gholitabar, S., and Roshan, V. D. (2013). Effect of treadmill exercise and Ferula gummosa on myocardial HSP72, vascular function, and antioxidant defenses in spontaneously hypertensive rats. Clin. Exp. Hypertens. 35, 347-354. doi: 10.3109/10641963.2012.732643

Gilani, A. H., Aziz, N., Khan, M. A., Shaheen, F., Jabeen, Q., Siddiqui, B. S., et al. (2000). Ethnopharmacological evaluation of the anticonvulsant, sedative and antispasmodic activities of Lavandula stoechas L. J. Ethnopharmacol. 71, 161-167. doi: 10.1016/S0378-8741(99)00198-1

Gilani, A. H., Jabeen, Q., Khan, A. U., and Shah, A. J. (2008). Gut modulatory, blood pressure lowering, diuretic and sedative activities of cardamom. J. Ethnopharmacol. 115, 463-472. doi: 10.1016/j.jep.2007.10.015

Gong, Y., Li, Y., Abdolmaleky, H. M., Li, L., and Zhou, J. R. (2012). Tanshinones inhibit the growth of breast cancer cells through epigenetic modification of Aurora A expression and function. PLoS ONE 7:e33656. doi: 10.1371/journal.pone.0033656

González-Peña, D., Angulo, J., Vallejo, S., Colina-Coca, C., de Ancos, B., SanchezFerrer, C. F., et al. (2014). High-cholesterol diet enriched with onion affects endothelium-dependent relaxation and NADPH oxidase activity in mesenteric microvessels from Wistar rats. Nutr. Metab. (Lond). 11:57. doi: 10.1186/17437075-11-57

Goto, H., Shimada, Y., Tanigawa, K., Sekiya, N., Shintani, T., and Terasawa, K. (1999). Effect of Uncariae ramulus et Uncus on endothelium in spontaneously hypertensive rats. Am. J. Chin. Med. 27, 339-345. doi: $10.1142 /$ S0192415X99000380

Gu, W. L., and Chen, C. X. (2008). [The study of Xuanshen on ventricular remodeling and cardiac endothelin-1 expression in rats treated with pressureoverload]. Zhong Yao Cai 31, 393-396.

Guo, W., Wise, M. L., Collins, F. W., and Meydani, M. (2008). Avenanthramides, polyphenols from oats, inhibit IL-1beta-induced NFkappaB activation in endothelial cells. Free Radic. Biol. Med. 44, 415-429. doi: 10.1016/j.freeradbiomed.2007.10.036

Hasrat, J. A., Pieters, L., and Vlietinck, A. J. (2004). Medicinal plants in Suriname: hypotensive effect of Gossypium barbadense. J. Pharm. Pharmacol. 56, 381-387. doi: $10.1211 / 0022357022917$

He, J., Jing, Z., and Gu, Q. (1999). [Collagen expression of intra-acinar pulmonary arteries and right ventricle and intervention of Radix Astragali in rats with hypoxic pulmonary hypertension]. Zhonghua Yi Xue Za Zhi 79, 654-656.

Hoe, S. Z., Kamaruddin, M. Y., and Lam, S. K. (2007). Inhibition of angiotensinconverting enzyme activity by a partially purified fraction of Gynura procumbens in spontaneously hypertensive rats. Med. Princ. Pract. 16, 203-208. doi: 10.1159/000100391

Hoe, S. Z., Lee, C. N., Mok, S. L., Kamaruddin, M. Y., and Lam, S. K. (2011). Gynura procumbens Merr. decreases blood pressure in rats by vasodilatation via inhibition of calcium channels. Clinics 66, 143-150. doi: 10.1590/S180759322011000100025
Horigome, S., Yoshida, I., Ito, S., Inohana, S., Fushimi, K., Nagai, T., et al. (2015). Inhibitory effects of Kaempferia parviflora extract on monocyte adhesion and cellular reactive oxygen species production in human umbilical vein endothelial cells. Eur. J. Nutr. doi: 10.1007/s00394-015-1141-5. [Epub ahead of print].

Hou, S. Z., Xu, S. J., Jiang, D. X., Chen, S. X., Wang, L. L., Huang, S., et al. (2012). Effect of the flavonoid fraction of Lithocarpus polystachyus Rehd. on spontaneously hypertensive and normotensive rats. J. Ethnopharmacol. 143, 441-447. doi: 10.1016/j.jep.2012.06.016

Hou, Y. Z., Zhao, G. R., Yuan, Y. J., Zhu, G. G., and Hiltunen, R. (2005). Inhibition of rat vascular smooth muscle cell proliferation by extract of Ligusticum chuanxiong and Angelica sinensis. J. Ethnopharmacol. 100, 140-144. doi: 10.1016/j.jep.2005.01.051

Houston, M. C. (2005). Nutraceuticals, vitamins, antioxidants, and minerals in the prevention and treatment of hypertension. Prog. Cardiovasc. Dis. 47, 396-449. doi: 10.1016/j.pcad.2005.01.004

Hsieh, H. Y., Chiu, P. H., and Wang, S. C. (2013). Histone modifications and traditional Chinese medicinals. BMC Complement. Altern. Med. 13:115. doi: $10.1186 / 1472-6882-13-115$

Hu, B., Zhang, H., Meng, X., Wang, F., and Wang, P. (2014). Aloe-emodin from rhubarb (Rheum rhabarbarum) inhibits lipopolysaccharide-induced inflammatory responses in RAW264.7 macrophages. J. Ethnopharmacol. 153, 846-853. doi: 10.1016/j.jep.2014.03.059

Huang, E. C., Zhao, Y., Chen, G., Baek, S. J., McEntee, M. F., Minkin, S., et al. (2014). Zyflamend, a polyherbal mixture, down regulates class I and class II histone deacetylases and increases p21 levels in castrate-resistant prostate cancer cells. BMC Complement. Altern. Med. 14:68. doi: 10.1186/1472-68 82-14-68

Hwang, S. M., Kim, J. S., Lee, Y. J., Yoon, J. J., Lee, S. M., Kang, D. G., et al. (2012). Anti-diabetic atherosclerosis effect of Prunella vulgaris in $\mathrm{db} / \mathrm{db}$ mice with type 2 diabetes. Am. J. Chin. Med. 40, 937-951. doi: 10.1142/S0192415X12500693

Ibarrola, D. A., Hellión-lbarrola, M. C., Montalbetti, Y., Heinichen, O., Alvarenga, N., Figueredo, A., and Ferro, E. A. (2000). Isolation of hypotensive compounds from Solanum sisymbriifolium Lam. J. Ethnopharmacol. 70, 301-307. doi: 10.1016/S0378-8741(00)00191-4

Ibarrola, D. A., Hellion-Ibarrola, M. C., Montalbetti, Y., Heinichen, O., Campuzano, M. A., Kennedy, M. L., et al. (2011). Antihypertensive effect of nuatigenin-3-O-beta-chacotriose from Solanum sisymbriifolium Lam. (Solanaceae) (nuati pyta) in experimentally hypertensive (ARH+DOCA) rats under chronic administration. Phytomedicine 18, 634-640. doi: 10.1016/j.phymed.2011.01.012

Ibarrola, D. A., Ibarrola, M. H., Vera, C., Montalbetti, Y., and Ferro, E. A. (1996). Hypotensive effect of crude root extract of Solanum sisymbriifolium (Solanaceae) in normo- and hypertensive rats. J. Ethnopharmacol. 54, 7-12. doi: 10.1016/0378-8741(96)01442-0

Iorio, M. V., Piovan, C., and Croce, C. M. (2010). Interplay between microRNAs and the epigenetic machinery: an intricate network. Biochim. Biophys. Acta 1799, 694-701. doi: 10.1016/j.bbagrm.2010.05.005

Ivanova, D., Tasinov, O., and Kiselova-Kaneva, Y. (2014). Improved lipid profile and increased serum antioxidant capacity in healthy volunteers after Sambucus ebulus L. fruit infusion consumption. Int. J. Food Sci. Nutr. 65, 740-744. doi: 10.3109/09637486.2014.898256

Jadhav, N., Patil, C. R., Chaudhari, K. B., Wagh, J. P., Surana, S. J., and Jadhav, R. B. (2010). Diuretic and natriuretic activity of two mistletoe species in rats. Pharmacognosy Res. 2, 50-57. doi: 10.4103/0974-8490.60576

Jeong, J. B., Park, J. H., Lee, H. K., Ju, S. Y., Hong, S. C., Lee, J. R., et al. (2009). Protective effect of the extracts from Cnidium officinale against oxidative damage induced by hydrogen peroxide via antioxidant effect. Food Chem. Toxicol. 47, 525-529. doi: 10.1016/j.fct.2008.11.039

Jin, S. E., Son, Y. K., Min, B. S., Jung, H. A., and Choi, J. S. (2012) Anti-inflammatory and antioxidant activities of constituents isolated from Pueraria lobata roots. Arch. Pharm. Res. 35, 823-837. doi: 10.1007/s12272-0120508-x

Kalaivani, P., Saranya, R. B., Ramakrishnan, G., Ranju, V., Sathiya, S., Gayathri, V., et al. (2013). Cuminum cyminum, a dietary spice, attenuates hypertension via endothelial nitric oxide synthase and NO pathway in renovascular hypertensive rats. Clin. Exp. Hypertens. 35, 534-542. doi: 10.3109/10641963.2013.764887

Kamkaew, N., Scholfield, C. N., Ingkaninan, K., Maneesai, P., Parkington, H. C., Tare, M., et al. (2011). Bacopa monnieri and its constituents is hypotensive in 
anaesthetized rats and vasodilator in various artery types. J. Ethnopharmacol. 137, 790-795. doi: 10.1016/j.jep.2011.06.045

Karuna, R., Reddy, S. S., Baskar, R., and Saralakumari, D. (2009). Antioxidant potential of aqueous extract of Phyllanthus amarus in rats. Indian J. Pharmacol. 41, 64-67. doi: 10.4103/0253-7613.51342

Kassuya, C. A., Leite, D. F., de Melo, L. V., Rehder, V. L., and Calixto, J. B. (2005). Anti-inflammatory properties of extracts, fractions and lignans isolated from Phyllanthus amarus. Planta Med. 71, 721-726. doi: 10.1055/s-2005871258

Kaur, T., Hussain, K., Koul, S., Vishwakarma, R., and Vyas, D. (2013). Evaluation of nutritional and antioxidant status of Lepidium latifolium Linn.: a novel phytofood from Ladakh. PLoS ONE 8:e69112. doi: 10.1371/journal.pone.0069112

Kaurinovic, B., Popovic, M., Vlaisavljevic, S., and Trivic, S. (2011). Antioxidant capacity of Ocimum basilicum L. and Origanum vulgare L. extracts. Molecules 16, 7401-7414. doi: 10.3390/molecules16097401

Khan, A. U., Mustafa, M. R., Khan, A. U., and Murugan, D. D. (2012). Hypotensive effect of Gentiana floribunda is mediated through Ca++ antagonism pathway. BMC Complement. Altern. Med. 12:121. doi: 10.1186/1472-6882-12-121

Khonsung, P., Panthong, A., Chiranthanut, N., and Intahphuak, S. (2011). Hypotensive effect of the water extract of the leaves of Pseuderanthemum palatiferum. J. Nat. Med. 65, 551-558. doi: 10.1007/s11418-011-0540-z

Kiemer, A. K., Hartung, T., Huber, C., and Vollmar, A. M. (2003). Phyllanthus amarus has anti-inflammatory potential by inhibition of iNOS, COX-2, and cytokines via the NF-kappaB pathway. J. Hepatol. 38, 289-297. doi: 10.1016/S0168-8278(02)00417-8

Kim, B. R., Seo, H. S., Ku, J. M., Kim, G. J., Jeon, C. Y., Park, J. H., et al. (2013). Silibinin inhibits the production of pro-inflammatory cytokines through inhibition of NF-kappaB signaling pathway in HMC-1 human mast cells. Inflamm. Res. 62, 941-950. doi: 10.1007/s00011-013-0640-1

Kim, D., Yokozawa, T., Hattori, M., Kadota, S., and Namba, T. (2000). Effects of aqueous extracts of Apocynum venetum leaves on spontaneously hypertensive, renal hypertensive and $\mathrm{NaCl}-$ fed-hypertensive rats. J. Ethnopharmacol. 72, 53-59. doi: 10.1016/S0378-8741(00)00197-5

Kim, E. Y., Jho, H. K., Kim, D. I., and Rhyu, M. R. (2008). Cirsium japonicum elicits endothelium-dependent relaxation via histamine $\mathrm{H}(1)$-receptor in rat thoracic aorta. J. Ethnopharmacol. 116, 223-227. doi: 10.1016/j.jep.2007.11.002

Kim, H. Y., Oh, H., Li, X., Cho, K. W., Kang, D. G., and Lee, H. S. (2011). Ethanol extract of seeds of Oenothera odorata induces vasorelaxation via endothelium-dependent NO-cGMP signaling through activation of Akt-eNOSsGC pathway. J. Ethnopharmacol. 133, 315-323. doi: 10.1016/j.jep.2010.09.024

Kim, K. H., Kim, C. S., Park, Y. J., Moon, E., Choi, S. U., Lee, J. H., et al. (2015). Anti-inflammatory and antitumor phenylpropanoid sucrosides from the seeds of Raphanus sativus. Bioorg. Med. Chem. Lett. 25, 96-99. doi: 10.1016/j.bmcl.2014.11.001

Kim, M. J., Lee, H. J., Wiryowidagdo, S., and Kim, H. K. (2006). Antihypertensive effects of Gynura procumbens extract in spontaneously hypertensive rats. J. Med. Food 9, 587-590. doi: 10.1089/jmf.2006.9.587

Kirk, H., Cefalu, W. T., Ribnicky, D., Liu, Z., and Eilertsen, K. J. (2008). Botanicals as epigenetic modulators for mechanisms contributing to development of metabolic syndrome. Metab. Clin. Exp. 57, S16-S23. doi: 10.1016/j.metabol.2008.03.006

Kochar, J., Gaziano, J. M., and Djousse, L. (2012). Breakfast cereals and risk of hypertension in the Physicians' Health Study I. Clin. Nutr. 31, 89-92. doi: 10.1016/j.clnu.2011.08.001

Koh, S. B., Kang, M. H., Kim, T. S., Park, H. W., Park, C. G., Seong, Y. H., et al. (2007). Endothelium-dependent vasodilatory and hypotensive effects of Crotalaria sessiliflora L. in rats. Biol. Pharm. Bull. 30, 48-53. doi: 10.1248/bpb.30.48

Kook, S. H., Choi, K. C., Lee, Y. H., Cho, H. K., and Lee, J. C. (2014). Raphanus sativus L. seeds prevent LPS-stimulated inflammatory response through negative regulation of the p38 MAPK-NF-kappaB pathway. Int. Immunopharmacol. 23, 726-734. doi: 10.1016/j.intimp.2014.11.001

Kosar, M., Bozan, B., Temelli, F., and Baser, K. H. C. (2007). Antioxidant activity and phenolic composition of sumac (Rhus coriaria L.) extracts. Food Chem. 103, 952-959. doi: 10.1016/j.foodchem.2006.09.049

Koyama, N., Suzuki, K., Furukawa, Y., Arisaka, H., Seki, T., Kuribayashi, K., et al. (2009). Effects of safflower seed extract supplementation on oxidation and cardiovascular risk markers in healthy human volunteers. Br. J. Nutr. 101, 568-575. doi: 10.1017/S0007114508025786

Kumar, K., Sharma, Y. P., Manhas, R. K., and Bhatia, H. (2015). Ethnomedicinal plants of Shankaracharya Hill, Srinagar, J\&K, India. J. Ethnopharmacol. 170, 255-274. doi: 10.1016/j.jep.2015.05.021

Kuo, Y. J., Yang, Y. C., Zhang, L. J., Wu, M. D., Kuo, L. M., Kuo, Y. C., et al. (2010). Flavanone and diphenylpropane glycosides and glycosidic acyl esters from Viscum articulatum. J. Nat. Prod. 73, 109-114. doi: 10.1021/np9004294

Lahlou, S., de Barros Correia, C. A. Jr., Vasconcelos Dos Santos, M., David, J. M., David, J. P., Duarte, G. P., et al. (2007). Mechanisms underlying the cardiovascular effects of a labdenic diterpene isolated from Moldenhawera nutans in normotensive rats. Vascul. Pharmacol. 46, 60-66. doi: 10.1016/j.vph.2006.06.010

Lahlou, S., Interaminense, L. F., Leal-Cardoso, J. H., and Duarte, G. P. (2003). Antihypertensive effects of the essential oil of Alpinia zerumbet and its main constituent, terpinen-4-ol, in DOCA-salt hypertensive conscious rats. Fundam. Clin. Pharmacol. 17, 323-330. doi: 10.1046/j.1472-8206.2003.00150.x

Lau, Y. S., Kwan, C. Y., Ku, T. C., Hsieh, W. T., Wang, H. D., Nishibe, S., et al. (2012). Apocynum venetum leaf extract, an antihypertensive herb, inhibits rat aortic contraction induced by angiotensin II: a nitric oxide and superoxide connection. J. Ethnopharmacol. 143, 565-571. doi: 10.1016/j.jep.2012.07.012

Lee, O. H., Kim, K. I., Han, C. K., Kim, Y. C., and Hong, H. D. (2012). Effects of acidic polysaccharides from gastrodia rhizome on systolic blood pressure and serum lipid concentrations in spontaneously hypertensive rats fed a high-fat diet. Int. J. Mol. Sci. 13, 698-709. doi: 10.3390/ijms13010698

Lee, Y. J., Choi, D. H., Cho, G. H., Kim, J. S., Kang, D. G., and Lee, H. S. (2012). Arctium lappa ameliorates endothelial dysfunction in rats fed with high fat/cholesterol diets. BMC Complement. Altern. Med. 12:116. doi: 10.1186/14726882-12-116

Lessa, M. A., Araújo, C. V., Kaplan, M. A., Pimenta, D., Figueiredo, M. R., and Tibirica, E. (2008). Antihypertensive effects of crude extracts from leaves of Echinodorus grandiflorus. Fundam. Clin. Pharmacol. 22, 161-168. doi: 10.1111/j.1472-8206.2008.00565.x

Li, J. W., Chen, P., Guan, X. Q., Gong, Y. S., and Yang, P. L. (2008). [Inhibition of puerarin on pulmonary hypertension in rats with hypoxia and hypercapnia]. Zhongguo Zhong Yao Za Zhi 33, 544-549.

Li, M., Guan, Y., Liu, J., Zhai, F., Zhang, X., and Guan, L. (2013). Cellular and molecular mechanisms in vascular smooth muscle cells by which total saponin extracted from Tribulus terrestris protects against artherosclerosis. Cell. Physiol. Biochem. 32, 1299-1308. doi: 10.1159/000354528

Lindner, E., Dohadwalla, A. N., and Bhattacharya, B. K. (1978). Positive inotropic and blood pressure lowering activity of a diterpene derivative isolated from Coleus forskohli: Forskolin. Arzneimittelforschung 28, 284-289.

Liu, S. J., Liu, Y., Zhang, X., Yang, Z. C., Liu, W. Z., and Tan, Y. Z. (2012). [Effect of TGRJ on blood press, NO and Ang II in renal hypertensive rats]. Zhong Yao Cai 35, 953-957.

Liu, W., Wang, L., Yu, J., Asare, P. F., and Zhao, Y. Q. (2015). Gastrodin reduces blood pressure by intervening with RAAS and PPARgamma in SHRs. Evid. Based Complement. Altern. Med. 2015:828427. doi: 10.1155/2015/ 828427

Liu, Y., Wang, G., Yang, M., Chen, H., Zhao, Y., Yang, S., et al. (2015). Arctigenin reduces blood pressure by modulation of nitric oxide synthase and NADPH oxidase expression in spontaneously hypertensive rats. Biochem. Biophys. Res. Commun. 468, 837-842. doi: 10.1016/j.bbrc.2015.11.041

Ma, Y. X., and Chen, S. Y. (1989). [Observations on the anti-aging, antihypertensive and antihyperlipemic effect of Apocynum venetum leaf extract]. Zhong Xi Yi Jie He Za Zhi 9, 335-337, 323.

Maghrani, M., Zeggwagh, N. A., Michel, J. B., and Eddouks, M. (2005). Antihypertensive effect of Lepidium sativum L. in spontaneously hypertensive rats. J. Ethnopharmacol. 100, 193-197. doi: 10.1016/j.jep.2005.02.024

Maity, S., Chatterjee, S., Variyar, P. S., Sharma, A., Adhikari, S., and Mazumder, S. (2013). Evaluation of antioxidant activity and characterization of phenolic constituents of Phyllanthus amarus root. J. Agric. Food Chem. 61, 3443-3450. doi: 10.1021/jf3046686

Malakul, W., Thirawarapan, S., Ingkaninan, K., and Sawasdee, P. (2011). Effects of Kaempferia parviflora wall. Ex baker on endothelial dysfunction in streptozotocin-induced diabetic rats. J. Ethnopharmacol. 133, 371-377. doi: 10.1016/j.jep.2010.10.011 
Marques, F. Z., Booth, S. A., and Charchar, F. J. (2015). The emerging role of noncoding RNA in essential hypertension and blood pressure regulation. J. Hum. Hypertens. 29, 459-467. doi: 10.1038/jhh.2014.99

Martin-Nizard, F., Sahpaz, S., Kandoussi, A., Carpentier, M., Fruchart, J. C., Duriez, P., et al. (2004). Natural phenylpropanoids inhibit lipoproteininduced endothelin-1 secretion by endothelial cells. J. Pharm. Pharmacol. 56, 1607-1611. doi: 10.1211/0022357045048

Mihailovic-Stanojevic, N., Belscak-Cvitanovic, A., Grujic-Milanovic, J., Ivanov, M., Jovovic, D., Bugarski, D., et al. (2013). Antioxidant and antihypertensive activity of extract from Thymus serpyllum $\mathrm{L}$. in experimental hypertension. Plant Foods Hum. Nutr. 68, 235-240. doi: 10.1007/s11130-0130368-7

Millis, R. M. (2011). Epigenetics and hypertension. Curr. Hypertens. Rep. 13, 21-28. doi: 10.1007/s11906-010-0173-8

Mirmiran, P., Bahadoran, Z., Golzarand, M., Rajab, A., and Azizi, F. (2013). Ardeh (Sesamum indicum) could improve serum triglycerides and atherogenic lipid parameters in type 2 diabetic patients: a randomized clinical trial. Arch. Iran. Med. 16, 652-656. doi: 0131611/AIM.008

Monteiro, F. S., Silva, A. C., Martins, I. R., Correia, A. C., Basilio, I. J., Agra, M. F., et al. (2012). Vasorelaxant action of the total alkaloid fraction obtained from Solanum paludosum Moric. (Solanaceae) involves NO/cGMP/PKG pathway and potassium channels. J. Ethnopharmacol. 141, 895-900. doi: 10.1016/j.jep.2012.03.032

Moon, M. K., Kang, D. G., Lee, A. S., Yeom, K. B., Kim, J. S., and Lee, H. S. (2008). Anti-atherogenic effects of the aqueous extract of rhubarb in rats fed an atherogenic diet. Am. J. Chin. Med. 36, 555-568. doi: $10.1142 /$ S0192415X08005977

Morimoto, T., Sunagawa, Y., Kawamura, T., Takaya, T., Wada, H., Nagasawa, A., et al. (2008). The dietary compound curcumin inhibits p300 histone acetyltransferase activity and prevents heart failure in rats. J. Clin. Invest. 118, 868-878. doi: 10.1172/jci33160

Muller, M. J., and Baer, H. P. (1983). Relaxant effects of forskolin in smooth muscle. Role of cyclic AMP. Naunyn-Schmiedeberg's Arch. Pharmacol. 322, 78-82. doi: 10.1007/BF00649356

Naseri, M. K., Arabian, M., Badavi, M., and Ahangarpour, A. (2008). Vasorelaxant and hypotensive effects of Allium cepa peel hydroalcoholic extract in rat. Pak. J. Biol. Sci. 11, 1569-1575. doi: 10.3923/pjbs.2008.1569.1575

Navarro, E., Alonso, J., Rodriguez, R., Trujillo, J., and Boada, J. (1994). Diuretic action of an aqueous extract of Lepidium latifolium L. J. Ethnopharmacol. 41, 65-69. doi: 10.1016/0378-8741(94)90059-0

Ng, C. F., Koon, C. M., Cheung, D. W., Lam, M. Y., Leung, P. C., Lau, C. B., et al. (2011). The anti-hypertensive effect of Danshen (Salvia miltiorrhiza) and Gegen (Pueraria lobata) formula in rats and its underlying mechanisms of vasorelaxation. J. Ethnopharmacol. 137, 1366-1372. doi: 10.1016/j.jep.2011.08.006

Ng, H. K., Poh, T. F., Lam, S. K., and Hoe, S. Z. (2013). Potassium channel openers and prostacyclin play a crucial role in mediating the vasorelaxant activity of Gynura procumbens. BMC Complement. Altern. Med. 13:188. doi: 10.1186/1472-6882-13-188

Nie, L., Wise, M., Peterson, D., and Meydani, M. (2006a). Mechanism by which avenanthramide-c, a polyphenol of oats, blocks cell cycle progression in vascular smooth muscle cells. Free Radic. Biol. Med. 41, 702-708. doi: 10.1016/j.freeradbiomed.2006.04.020

Nie, L., Wise, M. L., Peterson, D. M., and Meydani, M. (2006b). Avenanthramide, a polyphenol from oats, inhibits vascular smooth muscle cell proliferation and enhances nitric oxide production. Atherosclerosis 186, 260-266. doi: 10.1016/j.atherosclerosis.2005.07.027

Nie, P. H., Zhang, L., Zhang, W. H., Rong, W. F., and Zhi, J. M. (2012). The effects of hydroxysafflor yellow A on blood pressure and cardiac function. J. Ethnopharmacol. 139, 746-750. doi: 10.1016/j.jep.2011.11.054

Ntchapda, F., Barama, J., Kemeta Azambou, D. R., Etet, P. F., and Dimo, T. (2015). Diuretic and antioxidant activities of the aqueous extract of leaves of Cassia occidentalis (Linn.) in rats. Asian Pac. J. Trop. Med. 8, 685-693. doi: 10.1016/j.apjtm.2015.07.030

Nyadjeu, P., Dongmo, A., Nguelefack, T. B., and Kamanyi, A. (2011). Antihypertensive and vasorelaxant effects of Cinnamomum zeylanicum stem bark aqueous extract in rats. J. Complement. Integr. Med. 8. doi: 10.2202/15533840.1490
Nyadjeu, P., Nguelefack-Mbuyo, E. P., Atsamo, A. D., Nguelefack, T. B., Dongmo, A. B., and Kamanyi, A. (2013). Acute and chronic antihypertensive effects of Cinnamomum zeylanicum stem bark methanol extract in L-NAME-induced hypertensive rats. BMC Complement. Altern. Med. 13:27. doi: 10.1186/14726882-13-27

Ogawa, H., Sasai, N., Kamisako, T., and Baba, K. (2007). Effects of osthol on blood pressure and lipid metabolism in stroke-prone spontaneously hypertensive rats. J. Ethnopharmacol. 112, 26-31. doi: 10.1016/j.jep.2007.01.028

Ouedraogo, M., Ruiz, M., Vardelle, E., Carreyre, H., Coustard, J. M., Potreau, D., et al. (2011). From the vasodilator and hypotensive effects of an extract fraction from Agelanthus dodoneifolius (DC) Danser (Loranthaceae) to the active compound dodoneine. J. Ethnopharmacol. 133, 345-352. doi: 10.1016/j.jep.2010.10.002

Paran, E., Novack, V., Engelhard, Y. N., and Hazan-Halevy, I. (2009). The effects of natural antioxidants from tomato extract in treated but uncontrolled hypertensive patients. Cardiovasc. Drugs Ther. 23, 145-151. doi: 10.1007/s10557-008-6155-2

Park, J. M., Kim, S. D., Lee, W. M., Cho, J. Y., Park, H. J., Kim, T. W., et al. (2007). In vitro anti-oxidative and anti-inflammatory effects of solvent-extracted fractions from Suaeda asparagoides. Pharmazie 62, 453-458.

Phillips, O. A., Mathew, K. T., and Oriowo, M. A. (2006). Antihypertensive and vasodilator effects of methanolic and aqueous extracts of Tribulus terrestris in rats. J. Ethnopharmacol. 104, 351-355. doi: 10.1016/j.jep.2005.09.027

Poh, T. F., Ng, H. K., Hoe, S. Z., and Lam, S. K. (2013). Gynura procumbens causes vasodilation by inhibiting angiotensin II and enhancing bradykinin actions. J. Cardiovasc. Pharmacol. 61, 378-384. doi: 10.1097/FJC.0b013e31828685b3

Pourahmad, J., Eskandari, M. R., Shakibaei, R., and Kamalinejad, M. (2010). A search for hepatoprotective activity of aqueous extract of Rhus coriaria L. against oxidative stress cytotoxicity. Food Chem. Toxicol. 48, 854-858. doi: 10.1016/j.fct.2009.12.021

Prando, T. B., Barboza, L. N., Araujo, V. O., Gasparotto, F. M., de Souza, L. M., Lourenço, E. L., et al. (2015). Involvement of bradykinin B and muscarinic receptors in the prolonged diuretic and antihypertensive properties of Echinodorus grandiflorus (Cham. \& Schltdl.) Micheli. Phytomedicine. doi: 10.1016/j.phymed.2015.10.020. [Epub ahead of print].

Predes, F. S., Ruiz, A. L., Carvalho, J. E., Foglio, M. A., and Dolder, H. (2011). Antioxidative and in vitro antiproliferative activity of Arctium lappa root extracts. BMC Complement. Altern. Med. 11:25. doi: 10.1186/1472-6882-11-25

Preuss, H. G., Echard, B., Polansky, M. M., and Anderson, R. (2006). Whole cinnamon and aqueous extracts ameliorate sucrose-induced blood pressure elevations in spontaneously hypertensive rats. J. Am. Coll. Nutr. 25, 144-150. doi: 10.1080/07315724.2006.10719525

Qian, J. Q., Thoolen, M. J., van Meel, J. C., Timmermans, P. B., and van Zwieten, P. A. (1983). Hypotensive activity of tetrandrine in rats. Investigation into its mode of action. Pharmacology 26, 187-197. doi: 10.1159/000137801

Raimundo, J. M., Trindade, A. P., Velozo, L. S., Kaplan, M. A., Sudo, R. T., and Zapata-Sudo, G. (2009). The lignan eudesmin extracted from Piper truncatum induced vascular relaxation via activation of endothelial histamine $\mathrm{H} 1$ receptors. Eur. J. Pharmacol. 606, 150-154. doi: 10.1016/j.ejphar.2009.01.038

Raja, B., Kaviarasan, K., Arjunan, M. M., and Pugalendi, K. V. (2007). Effect of Melothria maderaspatana leaf-tea consumption on blood pressure, lipid profile, anthropometry, fibrinogen, bilirubin, and albumin levels in patients with hypertension. J. Altern. Complement. Med. 13, 349-354. doi: 10.1089/acm.2006.5373

Reuter, S., Gupta, S. C., Park, B., Goel, A., and Aggarwal, B. B. (2011). Epigenetic changes induced by curcumin and other natural compounds. Genes Nutr. 6, 93-108. doi: 10.1007/s12263-011-0222-1

Ried, K., Frank, O. R., and Stocks, N. P. (2009). Dark chocolate or tomato extract for prehypertension: a randomised controlled trial. BMC Complement. Altern. Med. 9:22. doi: 10.1186/1472-6882-9-22

Salahdeen, H. M., and Murtala, B. A. (2012). Vasorelaxant effects of aqueous leaf extract of Tridax procumbens on aortic smooth muscle isolated from the rat. J. Smooth Muscle Res. 48, 37-45. doi: 10.1540/jsmr.48.37

Saleh Al-Shehabi, T., Iratni, R., and Eid, A. H. (2015). Anti-atherosclerotic plants which modulate the phenotype of vascular smooth muscle cells. Phytomedicine. doi: 10.1016/j.phymed.2015.10.016. [Epub ahead of print].

Saltzman, E., Das, S. K., Lichtenstein, A. H., Dallal, G. E., Corrales, A., Schaefer, E. J., et al. (2001). An oat-containing hypocaloric diet reduces systolic blood 
pressure and improves lipid profile beyond effects of weight loss in men and women. J. Nutr. 131, 1465-1470.

Sankar, V., Pangayarselvi, B., Prathapan, A., and Raghu, K. G. (2013). Desmodium gangeticum (Linn.) DC. exhibits antihypertrophic effect in isoproterenol-induced cardiomyoblasts via amelioration of oxidative stress and mitochondrial alterations. J. Cardiovasc. Pharmacol. 61, 23-34. doi: 10.1097/FJC.0b013e3182756ad3

Schlepper, M., Thormann, J., and Mitrovic, V. (1989). Cardiovascular effects of forskolin and phosphodiesterase-III inhibitors. Basic Res. Cardiol. 84(Suppl. 1), 197-212. doi: 10.1007/BF02650360

Senejoux, F., Girard, C., Aisa, H. A., Bakri, M., Kerram, P., Berthelot, A., et al. (2012). Vasorelaxant and hypotensive effects of a hydroalcoholic extract from the fruits of Nitraria sibirica Pall. (Nitrariaceae). J. Ethnopharmacol. 141, 629-634. doi: 10.1016/j.jep.2011.08.012

Shah, A. J., and Gilani, A. H. (2009). Blood pressure-lowering and vascular modulator effects of Acorus calamus extract are mediated through multiple pathways. J. Cardiovasc. Pharmacol. 54, 38-46. doi: 10.1097/FJC.0b013e3181aa5781

Shankar, S., Kumar, D., and Srivastava, R. K. (2013). Epigenetic modifications by dietary phytochemicals: implications for personalized nutrition. Pharmacol. Ther. 138, 1-17. doi: 10.1016/j.pharmthera.2012.11.002

Sharifi, A. M., Darabi, R., and Akbarloo, N. (2003). Study of antihypertensive mechanism of Tribulus terrestris in $2 \mathrm{~K} 1 \mathrm{C}$ hypertensive rats: role of tissue ACE activity. Life Sci. 73, 2963-2971. doi: 10.1016/j.lfs.2003.04.002

Shen, X. C., Tao, L., Li, W. K., Zhang, Y. Y., Luo, H., and Xia, Y. Y. (2012). Evidencebased antioxidant activity of the essential oil from Fructus A. zerumbet on cultured human umbilical vein endothelial cells' injury induced by ox-LDL. BMC Complement. Altern. Med. 12:174. doi: 10.1186/1472-6882-12-174

Shi, C. C., Liao, J. F., and Chen, C. F. (2001). Comparative study on the vasorelaxant effects of three harmala alkaloids in vitro. Jpn. J. Pharmacol. 85, 299-305. doi: 10.1254/jjp.85.299

Shi, X., Mao, Y., Saffiotti, U., Wang, L., Rojanasakul, Y., Leonard, S. S., et al. (1995). Antioxidant activity of tetrandrine and its inhibition of quartzinduced lipid peroxidation. J. Toxicol. Environ. Health 46, 233-248. doi: 10.1080/15287399509532031

Siddiqi, H. S., Mehmood, M. H., Rehman, N. U., and Gilani, A. H. (2012). Studies on the antihypertensive and antidyslipidemic activities of Viola odorata leaves extract. Lipids Health Dis. 11:6. doi: 10.1186/1476-511X-11-6

Sinclair, K. D., Allegrucci, C., Singh, R., Gardner, D. S., Sebastian, S., Bispham, J., et al. (2007). DNA methylation, insulin resistance, and blood pressure in offspring determined by maternal periconceptional B vitamin and methionine status. Proc. Natl. Acad. Sci. U.S.A. 104, 19351-19356. doi: 10.1073/pnas.0707258104

Sohn, E. J., Kang, D. G., Mun, Y. J., Woo, W. H., and Lee, H. S. (2005). Antiatherogenic effects of the methanol extract of Sorbus cortex in atherogenic-diet rats. Biol. Pharm. Bull. 28, 1444-1449. doi: 10.1248/bpb.28.1444

Song, X. P., Chen, P. P., and Chai, X. S. (1988). [Effects of puerarin on blood pressure and plasma renin activity in spontaneously hypertensive rats]. Zhongguo Yao Li Xue Bao 9, 55-58.

Sosa, S., Altinier, G., Politi, M., Braca, A., Morelli, I., and Della Loggia, R. (2005). Extracts and constituents of Lavandula multifida with topical anti-inflammatory activity. Phytomedicine 12, 271-277. doi: 10.1016/j.phymed.2004.02.007

Souza, C. O., Peraçoli, M. T., Weel, I. C., Bannwart, C. F., Romao, M., NakairaTakahagi, E., et al. (2012). Hepatoprotective and anti-inflammatory effects of silibinin on experimental preeclampsia induced by L-NAME in rats. Life Sci. 91, 159-165. doi: 10.1016/j.lfs.2012.06.036

Srividya, N., and Periwal, S. (1995). Diuretic, hypotensive and hypoglycaemic effect of Phyllanthus amarus. Indian J. Exp. Biol. 33, 861-864.

Stefanska, B., Karlic, H., Varga, F., Fabianowska-Majewska, K., and Haslberger, A. (2012). Epigenetic mechanisms in anti-cancer actions of bioactive food components-the implications in cancer prevention. Br. J. Pharmacol. 167, 279-297. doi: 10.1111/j.1476-5381.2012.02002.x

Suh, S. J., Moon, S. K., and Kim, C. H. (2006). Raphanus sativus and its isothiocyanates inhibit vascular smooth muscle cells proliferation and induce $\mathrm{G}(1)$ cell cycle arrest. Int. Immunopharmacol. 6, 854-861. doi: 10.1016/j.intimp.2005.11.014
Sun, X. H., Ding, J. P., Li, H., Pan, N., Gan, L., Yang, X. L., et al. (2007). Activation of large-conductance calcium-activated potassium channels by puerarin: the underlying mechanism of puerarin-mediated vasodilation. J. Pharmacol. Exp. Ther. 323, 391-397. doi: 10.1124/jpet.107.125567

Sunagawa, Y., Morimoto, T., Wada, H., Takaya, T., Katanasaka, Y., Kawamura, T., et al. (2011). A natural p300-specific histone acetyltransferase inhibitor, curcumin, in addition to angiotensin-converting enzyme inhibitor, exerts beneficial effects on left ventricular systolic function after myocardial infarction in rats. Circ. J. 75, 2151-2159. doi: 10.1253/circj.CJ10-1072

Suresh Kumar, P., Patel, J. S., and Saraf, M. N. (2008). Mechanism of vasorelaxant activity of a fraction of root extract of Sesamum indicum Linn. Indian J. Exp. Biol. 46, 457-464.

Suzuki, K., Tsubaki, S., Fujita, M., Koyama, N., Takahashi, M., and Takazawa, K. (2010). Effects of safflower seed extract on arterial stiffness. Vasc. Health Risk Manag. 6, 1007-1014. doi: 10.2147/VHRM.S13998

Tabassum, N., and Ahmad, F. (2011). Role of natural herbs in the treatment of hypertension. Pharmacogn. Rev. 5, 30-40. doi: 10.4103/0973-7847.79097

Tahraoui, A., El-Hilaly, J., Israili, Z. H., and Lyoussi, B. (2007). Ethnopharmacological survey of plants used in the traditional treatment of hypertension and diabetes in south-eastern Morocco (Errachidia province). J. Ethnopharmacol. 110, 105-117. doi: 10.1016/j.jep.2006.09.011

Takimoto, T., Suzuki, K., Arisaka, H., Murata, T., Ozaki, H., and Koyama, N. (2011). Effect of $\mathrm{N}$-(p-coumaroyl)serotonin and $\mathrm{N}$-feruloylserotonin, major anti-atherogenic polyphenols in safflower seed, on vasodilation, proliferation and migration of vascular smooth muscle cells. Mol. Nutr. Food Res. 55, 1561-1571. doi: 10.1002/mnfr.201000545

Tanira, M. O., Ali, B. H., Bashir, A. K., Dhanasekaran, S., Tibirica, E. M., and Alves, L. M. (2000). Mechanism of the hypotensive action of Rhazya stricta leaf extract in rats. Pharmacol. Res. 41, 369-378. doi: 10.1006/phrs. 1999.0598

Tanira, M. O., Ali, B. H., Bashir, A. K., Wasfi, I. A., and Chandranath, I. (1996). Evaluation of the relaxant activity of some United Arab Emirates plants on intestinal smooth muscle. J. Pharm. Pharmacol. 48, 545-550. doi: 10.1111/j.2042-7158.1996.tb05971.x

Taqvi, S. I., Shah, A. J., and Gilani, A. H. (2008). Blood pressure lowering and vasomodulator effects of piperine. J. Cardiovasc. Pharmacol. 52, 452-458. doi: 10.1097/FJC.0b013e31818d07c0

Tep-Areenan, P., Sawasdee, P., and Randall, M. (2010). Possible mechanisms of vasorelaxation for 5,7-dimethoxyflavone from Kaempferia parviflora in the rat aorta. Phytother. Res. 24, 1520-1525. doi: 10.1002/ptr.3164

Tibiriçá, E., Almeida, A., Caillleaux, S., Pimenta, D., Kaplan, M. A., Lessa, M. A., et al. (2007). Pharmacological mechanisms involved in the vasodilator effects of extracts from Echinodorus grandiflorus. J. Ethnopharmacol. 111, 50-55. doi: 10.1016/j.jep.2006.10.030

Tirapelli, C. R., Ambrosio, S. R., de Oliveira, A. M., and Tostes, R. C. (2010). Hypotensive action of naturally occurring diterpenes: a therapeutic promise for the treatment of hypertension. Fitoterapia 81, 690-702. doi: $10.1016 /$ j.fitote.2010.05.018

Tomé-Carneiro, J., Larrosa, M., Yanez-Gascon, M. J., Davalos, A., Gil-Zamorano, J., Gonzalvez, M., et al. (2013). One-year supplementation with a grape extract containing resveratrol modulates inflammatory-related microRNAs and cytokines expression in peripheral blood mononuclear cells of type 2 diabetes and hypertensive patients with coronary artery disease. Pharmacol. Res. 72, 69-82. doi: 10.1016/j.phrs.2013.03.011

Turunen, M. P., Aavik, E., and Yla-Herttuala, S. (2009). Epigenetics and atherosclerosis. Biochim. Biophys. Acta 1790, 886-891. doi: 10.1016/j.bbagen.2009.02.008

Umar, A., Imam, G., Yimin, W., Kerim, P., Tohti, I., Berke, B., et al. (2010). Antihypertensive effects of Ocimum basilicum L. (OBL) on blood pressure in renovascular hypertensive rats. Hypertens. Res. 33, 727-730. doi: 10.1038/hr.2010.64

Vazquez-Prieto, M. A., Rodriguez Lanzi, C., Lembo, C., Galmarini, C. R., and Miatello, R. M. (2011). Garlic and onion attenuates vascular inflammation and oxidative stress in fructose-fed rats. J. Nutr. Metab. 2011, 475216. doi: $10.1155 / 2011 / 475216$

Veeramani, C., Al-Numair, K. S., Chandramohan, G., Alsaif, M. A., and Pugalendi, K. V. (2012). Protective effect of Melothria maderaspatana leaf fraction on 
electrolytes, catecholamines, endothelial nitric oxide synthase and endothelin1 peptide in uninephrectomized deoxycorticosterone acetate-salt hypertensive rats. J. Nat. Med. 66, 535-543. doi: 10.1007/s11418-011-0621-z

Veeramani, C., Aristatile, B., Pushpavalli, G., and Pugalendi, K. V. (2011). Effects of Melothria maderaspatana leaf extract on antioxidant status in sham-operated and uninephrectomized DOCA-salt hypertensive rats. Saudi J. Biol. Sci. 18, 99-105. doi: 10.1016/j.sjbs.2010.05.002

Verma, S. K., Jain, V., and Katewa, S. S. (2009). Blood pressure lowering, fibrinolysis enhancing and antioxidant activities of cardamom (Elettaria cardamomum). Indian J. Biochem. Biophys. 46, 503-506.

Verma, S. K., Jain, V., and Singh, D. P. (2012). Effect of Pueraria tuberosa DC. (Indian Kudzu) on blood pressure, fibrinolysis and oxidative stress in patients with stage 1 hypertension. Pak. J. Biol. Sci. 15, 742-747. doi: 10.3923/pjbs.2012.742.747

Visavadiya, N. P., Soni, B., and Dalwadi, N. (2009). Free radical scavenging and antiatherogenic activities of Sesamum indicum seed extracts in chemical and biological model systems. Food Chem. Toxicol. 47, 2507-2515. doi: 10.1016/j.fct.2009.07.009

Wang, G. J., Wu, X. C., Lin, Y. L., Ren, J., Shum, A. Y., Wu, Y. Y., et al. (2002). $\mathrm{Ca} 2+$ channel blocking effect of iso-S-petasin in rat aortic smooth muscle cells. Eur. J. Pharmacol. 445, 239-245. doi: 10.1016/S0014-2999(02)01764-8

Wang, J., Zhang, Q., Mei, X., and Zhang, X. (2014). Hydroxysafflor yellow A attenuates left ventricular remodeling after pressure overloadinduced cardiac hypertrophy in rats. Pharm. Biol. 52, 31-35. doi: 10.3109/13880209.2013.805791

Wang, T. T., Zhou, G. H., Kho, J. H., Sun, Y. Y., Wen, J. F., Kang, D. G., et al. (2013). Vasorelaxant action of an ethylacetate fraction of Euphorbia humifusa involves NO-cGMP pathway and potassium channels. J. Ethnopharmacol. 148, 655-663. doi: 10.1016/j.jep.2013.05.025

Wang, Z., Li, P., Wang, C., Jiang, Q., Zhang, L., Cao, Y., et al. (2016). Protective effects of Arctium lappa L. root extracts (AREs) on high fat diet induced quail atherosclerosis. BMC Complement. Altern. Med. 16, 6. doi: 10.1186/s12906-0160987-2

Wattanapitayakul, S. K., Chularojmontri, L., Herunsalee, A., Charuchongkolwongse, S., and Chansuvanich, N. (2008). Vasorelaxation and antispasmodic effects of Kaempferia parviflora ethanolic extract in isolated rat organ studies. Fitoterapia 79, 214-216. doi: 10.1016/j.fitote.2007.11.017

Wattanapitayakul, S. K., Suwatronnakorn, M., Chularojmontri, L., Herunsalee, A., Niumsakul, S., Charuchongkolwongse, S., et al. (2007). Kaempferia parviflora ethanolic extract promoted nitric oxide production in human umbilical vein endothelial cells. J. Ethnopharmacol. 110, 559-562. doi: 10.1016/j.jep.2006.09.037

Weerateerangkul, P., Palee, S., Chinda, K., Chattipakorn, S. C., and Chattipakorn, N. (2012). Effects of Kaempferia parviflora wall. Ex. Baker and sildenafil citrate on cGMP level, cardiac function, and intracellular $\mathrm{Ca} 2+$ regulation in rat hearts. J. Cardiovasc. Pharmacol. 60, 299-309. doi: 10.1097/FJC.0b013e3182 $609 \mathrm{a} 52$

Weerateerangkul, P., Surinkaew, S., Chattipakorn, S. C., and Chattipakorn, N. (2013). Effects of Kaempferia parviflora Wall. Ex. Baker on electrophysiology of the swine hearts. Indian J. Med. Res. 137, 156-163.

Wing, M. R., Devaney, J. M., Joffe, M. M., Xie, D., Feldman, H. I., Dominic, E. A., et al. (2014). DNA methylation profile associated with rapid decline in kidney function: findings from the CRIC study. Nephrol. Dial. Trans. 29, 864-872. doi: $10.1093 / \mathrm{ndt} / \mathrm{gft} 537$

Wong, T. M., Wu, S., Yu, X. C., and Li, H. Y. (2000). Cardiovascular actions of Radix Stephaniae Tetrandrae: a comparison with its main component, tetrandrine. Acta Pharmacol. Sin. 21, 1083-1088.

Woo, K. S., Yip, T. W. C., Chook, P., Kwong, S. K., Szeto, C. C., Li, J. K. Y., et al. (2013). Cardiovascular protective effects of adjunctive alternative medicine (Salvia miltiorrhiza and Pueraria lobata) in high-risk hypertension. Evid. Based Complement. Altern. Med. 2013:132912. doi: 10.1155/2013/ 132912

Wort, S. J., Ito, M., Chou, P. C., McMaster, S. K., Badiger, R., Jazrawi, E., et al. (2009). Synergistic induction of endothelin-1 by tumor necrosis factor alpha and interferon gamma is due to enhanced NF-kappaB binding and histone acetylation at specific kappaB sites. J. Biol. Chem. 284, 24297-24305. doi: 10.1074/jbc.M109.032524
Wright, C. I., Van-Buren, L., Kroner, C. I., and Koning, M. M. G. (2007). Herbal medicines as diuretics: a review of the scientific evidence. J. Ethnopharmacol. 114, 1-31. doi: 10.1016/j.jep.2007.07.023

Wu, H., Huang, M., Liu, Y., Shu, Y., and Liu, P. (2015). Luteolin Induces apoptosis by up-regulating miR-34a in human gastric cancer cells. Technol. Cancer Res. Treat. 14, 747-755. doi: 10.7785/tcrt.2012.500434

Wu, S. J., and Ng, L. T. (2007). Tetrandrine inhibits proinflammatory cytokines, iNOS and COX-2 expression in human monocytic cells. Biol. Pharm. Bull. 30, 59-62. doi: 10.1248/bpb.30.59

Xie, Q. M., Tang, H. F., Chen, J. Q., and Bian, R. L. (2002). Pharmacological actions of tetrandrine in inflammatory pulmonary diseases. Acta Pharmacol. Sin. 23, 1107-1113.

Xie, W., Zhang, X., Wang, T., and Hu, J. (2012). Botany, traditional uses, phytochemistry and pharmacology of Apocynum venetum L. (Luobuma): a review. J. Ethnopharmacol. 141, 1-8. doi: 10.1016/j.jep.2012.02.003

Xie, Y. W., Xu, H. X., Dong, H., Fiscus, R. R., and But, P. P. (2007). Role of nitric oxide in the vasorelaxant and hypotensive effects of extracts and purified tannins from Geum japonicum. J. Ethnopharmacol. 109, 128-133. doi: 10.1016/j.jep.2006.07.015

Xu, Z., Wang, X., Dai, Y., Kong, L., Wang, F., Xu, H., et al. (2010). (+/-)Praeruptorin A enantiomers exert distinct relaxant effects on isolated rat aorta rings dependent on endothelium and nitric oxide synthesis. Chem. Biol. Interact. 186, 239-246. doi: 10.1016/j.cbi.2010.04.024

Xue, Y., Wang, Y., Feng, D. C., Xiao, B. G., and Xu, L. Y. (2008). Tetrandrine suppresses lipopolysaccharide-induced microglial activation by inhibiting NFkappaB pathway. Acta Pharmacol. Sin. 29, 245-251. doi: 10.1111/j.17457254.2008.00734.x

Yadav, J. P., Arya, V., Yadav, S., Panghal, M., Kumar, S., and Dhankhar, S. (2010). Cassia occidentalis L.: a review on its ethnobotany, phytochemical and pharmacological profile. Fitoterapia 81, 223-230. doi: 10.1016/j.fitote.2009.09.008

Yang, M. D., Chiang, Y. M., Higashiyama, R., Asahina, K., Mann, D. A., Mann, J., et al. (2012). Rosmarinic acid and baicalin epigenetically derepress peroxisomal proliferator-activated receptor gamma in hepatic stellate cells for their antifibrotic effect. Hepatology 55, 1271-1281. doi: 10.1002/hep.24792

Yang, Q., Sun, M., Ramchandran, R., and Raj, J. U. (2015). IGF-1 signaling in neonatal hypoxia-induced pulmonary hypertension: role of epigenetic regulation. Vascul. Pharmacol. 73, 20-31. doi: 10.1016/j.vph.2015.04.005

Yang, Y., Cheng, X., Tian, W., Zhou, B., Wu, X., Xu, H., et al. (2014). MRTF-A steers an epigenetic complex to activate endothelin-induced proinflammatory transcription in vascular smooth muscle cells. Nucleic Acids Res. 42, 10460-10472. doi: 10.1093/nar/gku776

Yu, L., Yang, G., Weng, X., Liang, P., Li, L., Li, J., et al. (2015). Histone methyltransferase SET1 mediates angiotensin II-induced endothelin-1 transcription and cardiac hypertrophy in mice. Arterioscler. Thromb. Vasc. Biol. 35, 1207-1217. doi: 10.1161/ATVBAHA.115.305230

Yu, X. C., Wu, S., Chen, C. F., Pang, K. T., and Wong, T. M. (2004). Antihypertensive and anti-arrhythmic effects of an extract of Radix Stephaniae Tetrandrae in the rat. J. Pharm. Pharmacol. 56, 115-122. doi: $10.1211 / 0022357022458$

Zamblé, A., Yao, D., Martin-Nizard, F., Sahpaz, S., Offoumou, M., Bordet, R., et al. (2006). Vasoactivity and antioxidant properties of Microdesmis keayana roots. J. Ethnopharmacol. 104, 263-269. doi: 10.1016/j.jep.2005.09.016

Zawada, A. M., Rogacev, K. S., Hummel, B., Berg, J. T., Friedrich, A., Roth, H. J., et al. (2014). S-adenosylhomocysteine is associated with subclinical atherosclerosis and renal function in a cardiovascular low-risk population. Atherosclerosis 234, 17-22. doi: 10.1016/j.atherosclerosis.2014.02.002

Zhang, B., Niu, W., Xu, D., Li, Y., Liu, M., Wang, Y., et al. (2014). Oxymatrine prevents hypoxia- and monocrotaline-induced pulmonary hypertension in rats. Free Radic. Biol. Med. 69, 198-207. doi: 10.1016/j.freeradbiomed.2014.01.013

Zhang, K., Jiao, X. F., Li, J. X., and Wang, X. W. (2015). Rhein inhibits lipopolysaccharide-induced intestinal injury during sepsis by blocking the tolllike receptor 4 nuclear factor-kappaB pathway. Mol. Med. Rep. 12, 4415-4421. doi: 10.3892/mmr.2015.3925

Zhang, Q., Yang, Y. M., and Yu, G. Y. (2008). [Effects of gastrodin injection on blood pressure and vasoactive substances in treatment of old patients with 
refractory hypertension: a randomized controlled trial]. Zhong Xi Yi Jie He Xue Bao 6, 695-699. doi: 10.3736/jcim20080707

Zhang, X., Zhao, F., and Sheng, J. (2011). [Puerarin induced apoptosis of pulmonary artery smooth muscle cell by mitochondrial pathway]. Zhongguo Zhong Yao Za Zhi 36, 2255-2258.

Zhao, P., Su, G., Xiao, X., Hao, E., Zhu, X., and Ren, J. (2008). Chinese medicinal herb Radix Astragali suppresses cardiac contractile dysfunction and inflammation in a rat model of autoimmune myocarditis. Toxicol. Lett. 182, 29-35. doi: 10.1016/j.toxlet.2008.08.002

Zhao, W., Yu, J., Su, Q., Liang, J., Zhao, L., Zhang, Y., et al. (2013). Antihypertensive effects of extract from Picrasma quassiodes (D. Don) Benn. in spontaneously hypertensive rats. J. Ethnopharmacol. 145, 187-192. doi: 10.1016/j.jep.2012.10.049

Zhou, D., Liu, B., Xiao, X., Dai, P., Ma, S., and Huang, W. (2013). The effect of safflower yellow on spinal cord ischemia reperfusion injury in rabbits. Oxid. Med. Cell. Longev. 2013:692302. doi: 10.1155/2013/692302
Zhou, F., Zhong, W., Xue, J., Gu, Z. L., and Xie, M. L. (2012). Reduction of rat cardiac hypertrophy by osthol is related to regulation of cardiac oxidative stress and lipid metabolism. Lipids 47, 987-994. doi: 10.1007/s11745-012$3710-1$

Conflict of Interest Statement: The authors declare that the research was conducted in the absence of any commercial or financial relationships that could be construed as a potential conflict of interest.

Copyright $\odot 2016$ Anwar, Al Disi and Eid. This is an open-access article distributed under the terms of the Creative Commons Attribution License (CC BY). The use, distribution or reproduction in other forums is permitted, provided the original author(s) or licensor are credited and that the original publication in this journal is cited, in accordance with accepted academic practice. No use, distribution or reproduction is permitted which does not comply with these terms. 